\title{
Algunas reflexiones a propósito de la nueva vía en las causas de los santos*
}

\author{
Some Reflections on the New Way for the Causes of the Saints
}

Maria Victoria Hernández Rodríguez ${ }^{\text {a }}$

Pontificia Universidad Javeriana, Colombia

vhernandez@teletu.it

ORCID: https://orcid.org/0000-0002-9872-9312
DOI: https://doi.org/10.11144/Javeriana.syp38-75.arpn

Recibido: 15 Agosto 2018

Aceptado: 17 Septiembre 2018

Publicado: 30 Diciembre 2018

\section{Resumen:}

La traducción a lengua española de los primeros comentarios al motu proprio Maiorem hac dilectionem es motivo, en este artículo que la acompaña, para proponer algunas reflexiones sobre la nueva vía aprobada y promulgada por el Papa Francisco para las beatificaciones y canonizaciones. En concreto, se tratarán consideraciones concernientes a los criterios de prueba, establecidos en el art. 2 del motu proprio, como la locución adverbial "al menos" y "a corto plazo" y la expresión "ejercicio ordinario de las virtudes". Estas son cuestiones abiertas que la praxis de la Congregación para las Causas de los Santos perfilará y completará con esmero y prudencia a medida que examinará los supuestos que serán propuestos por esta nueva vía.

Palabras clave: santidad, beatificación, canonización, positio, ofrecimiento de la vida, Maiorem hac dilectionem, virtud heroica, martirio, caridad, acto heroico, fama de santidad.

\begin{abstract}
:
Translation into Spanish of the first comments to the motu proprio Maiorem hac dilectionem is the starting point herein to propose some reflections on the New Way approved and enacted by Pope Francis regarding the beatification and canonization. Specifically, this work addresses the considerations concerning the proving criteria provided in Article 2 of the motu proprio, like the adverbial phrases "at least" and "short-term" and the expression "ordinary exercise of the virtues". These are open questions that the praxis of the Congregation for the Causes of the Saints will defined and complete prudently and carefully, while examining the assumptions to be proposed by this New Way.
\end{abstract}

Keywords: sanctity, beatification, canonization, positio, offer one's life, Maiorem hac dilectionem, heroic virtue, martyrdom, charity, heroic act, fame of sanctity.

\section{Introducción}

A finales de 2017 vieron la luz algunas de las primeras intervenciones cualificadas sobre la carta apostólica del Papa Francisco, dadas en forma de motu proprio Maiorem hac dilectionem $(2017)^{\left[{ }^{* *}\right]}$ y recogidas en un pequeño volumen titulado L'offerta della vita nelle cause dei santi, publicado por la Congregación para las Causas de los Santos en la editorial Libreria Editrice Vaticana $(2017)^{[+t]}$. Con la expresa autorización de los autores, ofrecemos ahora a los estudiosos y expertos en esta materia de las causas de los santos el texto íntegro de dichas intervenciones, traducidas en lengua española y con la misma finalidad de la publicación italiana, expuesta en su presentación. Son tres contribuciones cuya publicación y difusión ayudan a comprender y profundizar en el motu proprio pontificio, ya sea desde sus contenidos o en vista de su aplicación en la praxis procedimental de las causas de los santos (Francisco, 2017).

El valor de dicha publicación reside en la autoridad de los mismos autores: el cardenal Angelo Amato, S. D. B., prefecto de la Congregación, y el arzobispo Marcello Bartolucci, secretario de la misma. Además, el documento lleva una breve presentación a cargo del P. Vincenzo Criscuolo, OFMCap, relator general de dicha Congregación. Al motu proprio del Papa Francisco le siguen tres intervenciones publicadas, las dos primeras,

Notas de autor 
en L'Osservatore Romano, mientras que la última es la conferencia pronunciada en Roma el 20 de noviembre de 2017 con ocasión del encuentro formativo organizado por el Colegio de Postuladores ${ }^{[\neq \ddagger]}$.

Mons. Bartolucci fue el primero en ofrecer una presentación y un comentario al motu proprio, precisamente al día siguiente de su promulgación. Este contaba con el mismo objetivo del pequeño pero denso libro que ahora presentamos, es decir, el de aportar algunas contribuciones específicas para encuadrar históricamente el documento pontificio, aclarando la génesis histórica y profundizando en las motivaciones teológicas.

El reconocimiento de la cuarta vía como expresión de santidad canonizable ha seguido un recorrido lento, pero fino a su maduración y confirmación por parte del Romano Pontífice. En el comentario al texto, Mons. Bartolucci (2017a) explica todo el procedimiento que se siguió hasta la aprobación pontificia. Ante todo, es necesario recordar que, en sí mismo, el ofrecimiento de la vida no supone alguna novedad en las causas de los santos; sin embargo, sí lo es para las características requeridas por el motu proprio en su constitución como vía en sí misma. La vía del ofrecimiento de la vida es nueva desde el punto de vista jurídico-canónico, pero afonda sus raíces en las enseñanzas de Benedicto XIV, obviamente no como vía sino como posibilidad de reconocer la santidad canonizada a quienes habían dado la vida en un extremo acto de caridad. Efectivamente, Próspero Lambertini hace referencia al ofrecimiento de la vida seguido de la muerte segura, para lo que pone como ejemplo a quienes, habiendo ofrecido su vida en un acto de caridad, morían a causa del contagio por la asistencia a los apestados. En este sentido, se pueden recordar los casos de san Jerónimo Emiliani, san Luis Gonzaga y san Damián de Veuster. La diferencia entre la posibilidad mencionada por el Magister y la actual cuarta vía está en que los requisitos a demostrar eran, entonces, los mismos que para el ejercicio heroico de las virtudes, mientras que la cuarta vía sigue en este aspecto un esquema probatorio diferente, específico.

Volviendo al iter de elaboración y aprobación del motu proprio, solo en el Congreso Ordinario ${ }^{[\$ \$]}$ del 24 de enero de 2014 la nueva vía fue objeto de estudio directo y explícito, con el apoyo del Santo Padre. El estudio de dicho argumento dio lugar a una Positio peculiaris ${ }^{[* *]}$, con las contribuciones complementarias de cinco estudiosos de las causas de los santos: un biblista, un docente de teología dogmática, un especialista en teología espiritual, un canonista y un especialista en historia. Además, el 2 de junio de 2016, se incluyó un Congreso Peculiar ${ }^{[\dagger+\dagger]}$ en el que intervinieron 15 expertos, entre ellos 10 consultores $^{[\neq \neq \neq]}$y 5 postuladores. En dicho congreso se discutió sobre las cinco preguntas que la Congregación para las Causas de los Santos había formulado y propuesto (Bartolucci, 2017a) y a las que cada uno de los expertos había respondido por escrito. Todo ello fue recogido en Relatio et Vota Congressus Peculiaris, para el estudio por parte de la Sesión Plenaria

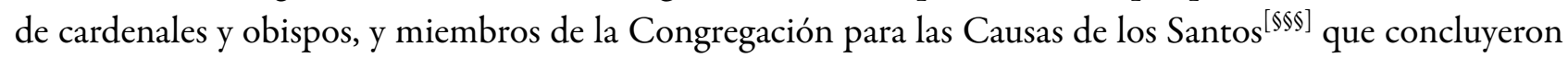
dando una respuesta afirmativa a la nueva vía para la beatificación de quien ha ofrecido la vida en un acto de caridad. El resultado fue sometido al Santo Padre, quien lo aprobó el 17 de enero de 2017, disponiendo que se procediese a la elaboración del texto, es decir, de lo que hoy es el motu proprio Maiorem hac dilectionem (Bartolucci, 2017a).

En el mencionado Congreso Peculiar, Mons. Bartolucci expone el resultado de la discusión que se llevó a cabo. En concreto, recuerda el Prelado sobre la falta de unanimidad entre los consultores teólogos y postuladores en referencia a los aspectos sobre los que la Congregación había formulado una serie de cuestiones para responder, como la distinción de la nueva vía de aquella de las virtudes heroicas y del martirio, es decir, si la nueva vía que se proponía podía considerarse una vía en sí misma (Bartolucci, 2017a). La mayor parte de los consultores se pronunció a favor, mientras que una minoría dio respuesta negativa o contraria a la constitución de una vía independiente, una vía en sí misma. Sobre la necesidad o no del milagro también hubo una minoría de consultores que se pronunció a favor de la no necesidad de tal prueba (Bartolucci, 2017a).

Sería interesante conocer si las respuestas negativas provenían de los mismos consultores tanto para la primera como para la segunda pregunta, así como su motivación para verificar si existe algún vínculo o conexión entre la respuesta negativa y la necesidad del milagro, y la respuesta negativa y la distinción como vía independiente. Es obvio que si el ofrecimiento heroico de la vida, sugerido y sostenido por la caridad, expresa 
una imitación verdadera, completa y ejemplar de Cristo como la expresa también el martirio, y por ello podría ser considerada a modo de martirio, no es necesario el milagro. Por otra parte, podría existir algún vínculo entre la respuesta negativa y la necesidad del milagro o la identificación de esta nueva vía con la del ejercicio heroico de las virtudes teologales, cardinales y anejas.

Parece obvio que las cuestiones planteadas a los consultores no se apoyaban en los requisitos o criterios de prueba indicados sucesivamente por el motu proprio en el artículo 2; es decir, probablemente, estos han sido elaborados posteriormente sobre la base de las intervenciones contenidas en la Positio peculiar proporcionadas por los consultores y los miembros de la Congregación. Dichas intervenciones serán siempre una orientación válida para interpretar con certeza aquellos criterios o requisitos, cuyo examen puede generar reflexiones e incluso dudas sobre algunos de ellos. Efectivamente, el conocimiento y la comprensión de las causas de beatificación y canonización por la vía del ofrecimiento de la vida requieren del examen previo de conceptos propios y específicos de esta materia, y de igual manera sucede con los conceptos requeridos en las demás vías que pueden seguirse para la beatificación y canonización, es decir, las llamadas "vías clásicas": el martirio y el ejercicio heroico de las virtudes (Bartolucci, 2017a).

En primer lugar, quisiera que nos detengamos en el significado de algunos adverbios, es decir, en el contexto objeto de estas reflexiones.

En las partes c y d del artículo 2 del motu proprio se usan las locuciones "por lo menos" y "al menos" (del latín minus); estas son locuciones adverbiales con idéntico significado: "aunque no sea otra cosa" y "aunque no sea más” (Real Academia Española, 2018). Aplicadas a nuestro caso, estas locuciones vendrían a significar que, aunque no se vaya más allá del grado ordinario en el ejercicio de las virtudes cristianas, el requisito n. 3 estaría probado y que si la fama de santidad no existe antes de la muerte, el criterio n. 4 estaría también superado. Es decir, no se podría poner objeción alguna a la existencia de unas virtudes vividas solo en grado ordinario ni tampoco se podría objetar sobre la falta de fama de santidad antes de la muerte.

Sin embargo, una ulterior dificultad derivaría de la medida atribuida al "ejercicio ordinario". ¿En qué consiste el "grado ordinario" del ejercicio de las virtudes cristianas? Si para la prueba del grado heroico se requieren circunstancias difíciles, perseverancia, gozo espiritual y prontitud en el ejercicio de las virtudes, nada de ello se requiere para el grado ordinario. Podríamos apelarnos para describir el grado del ejercicio virtuoso e interpretar la expresión "grado ordinario del ejercicio de las virtudes cristianas" al preámbulo del motu proprio, donde se habla de "seguimiento cercano de los pasos y de las enseñanzas del Señor Jesús", es decir, vivir según los dictámenes de Dios con un asentimiento pleno del intelecto y de la voluntad. De este modo, el ofrecimiento de la vida sería el culmen de una vivencia caracterizada por un constante crecimiento en la caridad.

La misma exhortación apostólica del Papa Francisco Gaudete et exsultate, sobre la llamada a la santidad en el mundo actual (Francisco, 2018), puede ser una ayuda para comprender la expresión "ejercicio ordinario" y para interpretar el criterio n. 3 del motu proprio, que se refiere a los límites entre los cuales se debe encuadrar dicho ejercicio virtuoso.

En cuanto vocación, el ofrecimiento no es fruto de la deliberación humana, sino que es don, iniciativa y llamado de Dios, como lo son el martirio y el ejercicio heroico de las virtudes; en ese sentido, es algo que no se improvisa, que requiere, como se lee efectivamente en el preámbulo, un seguimiento más de cerca de los pasos - ¡la imitación de Cristo! - y las enseñanzas del Señor. Una opción radical por Dios en la que son inseparables la ciencia del amor y la ciencia de la fe. Se requiere un habitus virtuoso para el martirio y el ejercicio heroico de las virtudes, por ende, también en el ofrecimiento de la vida. Ese habitus sería el ejercicio ordinario de las virtudes.

En lo que respecta al criterio expresado con la locución adverbial "corto plazo" (n. 1), es decir, "dentro de un periodo relativamente breve", no cabe duda de que es en sí mismo indeterminado y subjetivo ${ }^{[* * *]}$.

La dificultad se pone en la duración del periodo de tiempo que se puede interponer entre el ofrecimiento y la muerte, puesto que "corto plazo" no es de inmediato o inmediatamente, es decir, "sin interposición de otra cosa, ahora, al punto, al instante", aun siendo posible que la muerte acontezca en el mismo momento 
del ofrecimiento, es decir, "de inmediato". En esta circunstancia, no sería fácil demostrar un ejercicio alto y ejemplar de las virtudes, pues la dificultad está en la determinación o delimitación del periodo máximo, siempre y cuando no haya duda sobre el tiempo mínimo.

Por último, parece oportuno detenernos en la consideración de la edad. Es claro que la santidad no tiene edad, que niños y adolescentes pueden ser declarados santos confesores o mártires. En el ofrecimiento libre y voluntario de la vida y la heroica aceptación propter caritatem de una muerte segura y a corto plazo -escribe Mons. Bartolucci en el segundo artículo "L’amore più grande: dare la vita per i fratelli”-,

\begin{abstract}
es necesario que el ofrecimiento heroico no sea determinado por la impulsividad, por la infatuación, por la exaltación, por el exhibicionismo, por la ostentación, etc. Quien se ofrece deberá, además, saber anticipadamente a dónde va con su decisión y cuáles son las repercusiones que podrían darse en el necesitado. Deberá, además, considerar si el ofrecimiento de sí es evangélicamente prudente y proporcional a las necesidades del prójimo y al efecto beneficioso que podría efectivamente derivarse del mismo [...], deberá adherirse a la realidad del mismo modo como puede ser percibida por una mente sana, prudente, iluminada por la fe. (Bartolucci, 2017c)
\end{abstract}

La capacidad de un joven, mayor de edad, para dicho razonamiento y comprensión de las circunstancias (ayuda del prójimo necesitado de una concreta y bien definida cercanía y que, en caso de faltarle, sufriría graves daños) se puede dar por asentada, mas no sucede así en un preadoslescente o adolescente, en el que podría ponerse en duda. La semejanza con el martirio resolvería la dificultad que la edad adolescencial podría crear para la santidad canonizada si se sigue esta cuarta vía. No faltan adolescentes mártires canonizados, pues sabemos de: Cristóbal, Antonio y Juan, entre los 11 y los 14 años de edad (Tlaxcala-México), martirizados entre 1527-1529; José Sánchez del Río, 15 años (Zamora-México, 1928), y María Goretti,12 años (AlbanoItalia, 1902). También sabemos de jóvenes beatificados como: David Okelo y Gildo Irwa (16 y 12 años, GuluUganda, 1918), Albertina Berkenbrock (12 años, Florianópolis-Brasil, 1931) y Carolina Kozka (16 años, Tarnów-Polonia, 1914). Sin olvidar a santa Inés y san Tarcisio, mártires a los 13 y 14 años respectivamente. Cabe agregar que son numerosos los santos o beatos menores de edad entre los grupos de mártires chinos, japoneses y, sobre todo, españoles (Tagliaferri y Borer, 2017).

Las dos vías -el martirio y el ejercicio heroico de las virtudes- requieren la consciencia de ser llamados a ofrecer la vida por Cristo y la confrontación con la realidad personal, eclesial y social. Quien ofrece su vida es también consciente de ser llamado a ofrecerla por Cristo en un grande y heroico acto de amor, esta es la vía más noble para la santidad. Consciencia, reflexión, conciencia y libertad de la decisión de sacrificar la propia vida movido por un acto de caridad heroica hacia el prójimo en grave necesidad deponen fuertemente a favor de la seriedad de las convicciones y constituyen un importante signo de credibilidad para la comunidad eclesial, pues el fiel que ofrece la propia vida se convierte en modelo de vida cristiana, se transforma en imagen viva del Verbo encarnado.

No cabe la menor duda de que la prueba por excelencia sería la confesión directa de quien ofrece su vida, una verbal o escrita que exponga las intenciones de la consciencia ${ }^{[+t+]}$, de la necesidad del prójimo en una circunstancia grave que solo el ofrecimiento de la vida - con la consiguiente muerte segura a corto plazopodría salvarlo. Sin embargo, a esta confesión habría que agregarle la confesión extrajudicial, reportada en juicio por testigos de visu.

\title{
El ofrecimiento de la vida en las causas de los santos
}

Carta apostólica en forma de motu proprio Maiorem hac dilectionem sobre el ofrecimiento de la vida Nadie tiene mayor amor que el que da su vida por sus amigos

(Jn 15, 13). 
Son dignos de consideración y honor especial aquellos cristianos que, siguiendo más de cerca los pasos y las enseñanzas del Señor Jesús, han ofrecido voluntaria y libremente su vida por los demás y preservado hasta la muerte en este propósito.

Es cierto que el ofrecimiento heroico de la vida, sugerido y sostenido por la caridad, expresa una imitación verdadera, completa y ejemplar de Cristo y, por tanto, es merecedor de la admiración que la comunidad de los fieles suele reservar a los que han aceptado voluntariamente el martirio de sangre o han ejercido heroicamente las virtudes cristianas.

Confortado por la opinión favorable de la Congregación para las Causas de los Santos, que en el Pleno del 27 de septiembre de 2016 estudió cuidadosamente si estos cristianos merecen la beatificación, establezco que se observen las siguientes normas:

Art. 1

El ofrecimiento de la vida es un nuevo caso del iter de beatificación y canonización, distinto del caso de martirio y de heroicidad de las virtudes.

\section{Art. 2}

El ofrecimiento de la vida, para que sea válido y eficaz para la beatificación de un Siervo de Dios, debe cumplir con los siguientes criterios:

a) ofrecimiento libre y voluntario de la vida y heroica aceptación propter caritatem de una muerte segura y a corto plazo;

b) relación entre el ofrecimiento de la vida y la muerte prematura;

c) el ejercicio, por lo menos en grado ordinario, de las virtudes cristianas antes del ofrecimiento de la vida y, después, hasta la muerte;

d) existencia de la fama de santidad y de los signos, al menos después de la muerte, y

e) necesidad del milagro para la beatificación, sucedido después de la muerte del Siervo de Dios y por su intercesión.

\section{Art. 3}

La celebración de la investigación diocesana o eparquial y la relativa Positio están reguladas por la constitución apostólica Divinus perfectiones Magister del 25 de enero de 1983, en Acta Apostolicae Sedis, vol. LXXV (Juan Pablo II, 1983), y por las Normae servandae in inquisitionibus ab Episcopis facendis in Causis Sanctorum del 7 de febrero del mismo año, en Acta Apostolicae Sedis, vol. LXXV (Congregación para las Causas de los Santos, 1983), excepto en lo siguiente.

\section{Art. 4}

La Positio sobre el ofrecimiento de vida debe responder al dubium. An constet de heroica oblatione vitae usque ad mortem propter caritatem necnon de virtutibus christianis, saltem in gradu ordinario, in casu et ad effectum de quo agitur.

\section{Art. 5}

Los siguientes artículos de la citada constitución apostólica se modifican como sigue:

Art. 1:

"Compete a los obispos diocesanos y de más jerarquías equiparadas en derecho, dentro de los límites de su jurisdicción, sea de oficio, sea a instancias de fieles o de grupos legítimamente constituidos o de sus procuradores, el derecho a investigar sobre la vida, virtudes, ofrecimiento de la vida o martirio y fama de santidad, de ofrecimiento de la vida o martirio, milagros atribuidos, y, si se considera necesario, el antiguo culto al Siervo de Dios, cuya canonización se pide".

Art. 2.5:

"Hágase por separado el examen de los milagros atribuidos y el examen de las virtudes, del ofrecimiento de la vida o del martirio".

Art. 7.1: 
"Estudiar juntamente con los colaboradores externos las causas a ellos encomendadas y preparar las ponencias sobre las virtudes, sobre el ofrecimiento de la vida o sobre el martirio”.

Art 13.2:

"Determínese a qué relator ha de ser confiada la causa, si en dicho Congreso se juzgare que dicha causa ha sido instruida conforme a las normas de la ley; el relator, junto con un colaborador externo, elabore la ponencia sobre las virtudes, sobre el ofrecimiento de la vida o sobre el martirio según las reglas de la crítica que se observan en hagiografía”.

\section{Art. 6}

Los siguientes artículos de la mencionada Normae servandae in inquisitionibus ab Episcopis facendis in Causis Sanctorum se modifican como sigue:

Art. 7:

"La causa puede ser reciente o antigua. Será reciente si el martirio o las virtudes o el ofrecimiento de la vida del Siervo de Dios pueden probarse por las declaraciones orales de testigos oculares; será antigua si las pruebas sobre el martirio o sobre las virtudes sólo pueden fundarse en fuentes escritas".

Art. 10.1:

"Tanto en las causas recientes como en las antiguas, una biografía del Siervo de Dios, de cierto rigor histórico, si la hay; o, si no la hubiera, una relación muy cuidada, compuesta cronológicamente, sobre la vida y hechos del mismo Siervo de Dios, sobre sus virtudes o sobre el ofrecimiento de la vida o sobre el martirio, sobre la fama de santidad y de milagros, sin omitir cuanto parezca contrario o menos favorable a la misma causa”.

Art. 10.3:

"Solamente en las causas recientes [abra] una lista de personas que puedan ayudar a esclarecer la verdad sobre las virtudes o sobre el ofrecimiento de la vida o sobre el martirio del Siervo de Dios, sobre la fama de santidad o de milagros y también de las personas que se opongan a ello".

Art. 15a:

"Recibido este informe, el Obispo hará entrega al promotor de justicia, o a otro experto en estas cosas, de todo lo que hasta ahora ha ido recibiendo, a fin de que prepare unos interrogatorios apropiados para dilucidar la verdad sobre la vida del Siervo de Dios, sobre las virtudes, el ofrecimiento de la vida o el martirio, sobre la fama de santidad y de ofrecimiento de la vida o del martirio".

Art. 15b:

"En las causas antiguas, los interrogatorios se referirán únicamente a la fama de santidad, de ofrecimiento de la vida o del martirio que aún se dé en la actualidad y, si fuera el caso, al culto que se haya tributado al Siervo de Dios en los últimos tiempos”.

Art. 19:

"Para probar el martirio o el ejercicio de las virtudes, o el ofrecimiento de la vida, así como la fama de milagros de un Siervo de Dios que perteneció a un Instituto de vida consagrada, una parte notable de los testigos debe ser ajena al instituto, salvo que por la vida peculiar del Siervo de Dios eso no sea posible".

Art. 32:

"La investigación sobre los milagros ha de instruirse separadamente de la de las virtudes, del ofrecimiento de la vida o del martirio y ha de hacerse según las normas que siguen".

Art. 36:

"Se prohíben las solemnidades o panegíricos en las iglesias acerca de los Siervos de Dios cuya santidad de vida está aún sometida a legítimo examen. Y aun fuera de las iglesias, hay que abstenerse de cualquier acto que pueda inducir a los fieles a la falsa idea de que la investigación hecha por el Obispo sobre la vida y virtudes o el martirio o sobre el ofrecimiento de la vida del Siervo de Dios lleva consigo la certidumbre de su futura canonización".

Todo lo que he deliberado con esta carta apostólica en forma de motu proprio ordeno que se observe en todas sus partes; no obstante, cualquier disposición contraria, aunque digna de mención, establezco que se 
promulgue mediante la publicación en el diario L'Osservatore Romano, entrando en vigor el mismo día de la promulgación y que, sucesivamente, se incorpore al Acta Apostolicae Sedis.

Dado en Roma, en San Pedro, el día 11 de julio, quinto de Nuestro Pontificado.

Francisco

\section{Una cuarta vía para la beatificación[キ邦]}

\section{Marcello Bartolucci}

Con el motu proprio Maiorem hac dilectionem sobre el ofrecimiento de la vida, [el] Papa Francisco ha abierto la vía a la beatificación de aquellos fieles que, movidos por la caridad, han ofrecido heroicamente la propia vida por el prójimo, aceptando libre y voluntariamente una muerte cierta y prematura con la intención de seguir a Jesús: "Él ha dado la vida por nosotros; por eso nosotros debemos dar la vida por nuestros hermanos" (1 Jn 3,16).

\section{Las vías clásicas de la beatificación}

Como se sabe, ya desde hace siglos, las normas de la Iglesia católica prevén que se pueda proceder a la beatificación de un Siervo de Dios siguiendo una de estas tres vías:

1. La vía del martirio, que es la suprema imitación de Cristo y el testimonio más alto de la caridad. El concepto clásico de martirio comprende: a) por parte de la víctima, la aceptación voluntaria de la muerte violenta por amor a Cristo; b) el odium del perseguidor a la fe, o a otra virtud cristiana; c) la mansedumbre y el perdón de la víctima, que imita el ejemplo de Jesús, el cual sobre la cruz invocó la misericordia del Padre para sus asesinos.

2. La vía de las virtudes heroicas, ejercitadas "con prontitud, gozo espiritual, por encima del modo común de actuar y por un fin sobrenatural” (Benedicto XIV) y durante un congruo periodo de tiempo, es decir, hasta convertirlas en modo habitual de ser y de actuar conforme al Evangelio. Se trata de las virtudes teologales (fe, esperanza y caridad), cardinales (prudencia, justicia, fortaleza y templanza) y anejas (pobreza, obediencia, castidad y humildad).

3. Hay, en fin, una tercera vía, menos conocida y menos recorrida, que, sin embargo, conduce al mismo resultado que las otras dos. Es la vía de los llamados casus excepti, así denominados por el Código de Derecho Canónico de 1917 (Benedicto XV, 1917). Su reconocimiento lleva a la confirmación de un culto antiguo, es decir, sucesivo al pontificado de Alejandro III (años posteriores a 1181 y antecedente al 153, como estableció Urbano VIII (1623-1644), el gran legislador de las causas de los santos. La confirmación del culto antiguo es llamada también beatificación equipolente.

\section{Una nueva vía para la beatificación}

Estas tres vías están aún abiertas y se pueden seguir, pero no parece que sean suficientes para interpretar todos los casos posibles de santidad canonizable. En efecto, últimamente la Congregación para las Causas de los Santos se ha preguntado "si son merecedores de beatificación aquellos Siervos de Dios que, inspirados en el ejemplo de Cristo, hayan libre y voluntariamente querido ofrecer e inmolar la propia vida por los hermanos en un supremo acto de caridad, que haya sido directamente causa de muerte, poniendo así en práctica la palabra del Señor: Nadie tiene mayor amor que el que da su vida por sus amigos (Jn 15,13)" (Positio peculiaris, 3). 
Se trata de introducir una cuarta vía, que podríamos llamar del ofrecimiento de la vida. Aun teniendo algunos elementos que la asemejan, sea a la vía del martirio sea a la de las virtudes heroicas, es una vía nueva que pretende dar valor a un heroico testimonio cristiano, hasta ahora sin un procedimiento específico, precisamente porque no entra del todo en el caso del martirio y tampoco en el de las virtudes heroicas.

La vía del ofrecimiento de la vida, en efecto, se asemeja parcialmente a la del martirio porque conlleva el acto heroico del don de sí, hasta la muerte incluida, pero se diferencia porque no hay un perseguidor que pretenda imponer la elección contra Cristo. Del mismo modo, la vía del ofrecimiento de la vida se parece a la de las virtudes heroicas porque hay un acto heroico de caridad (el don de sí), inspirado en el ejemplo de Cristo, pero se diferencia porque no es la expresión de un prolongado ejercicio de las virtudes. Se requiere, de todas formas, un ejercicio ordinario de vida cristiana, que haga posible y comprensible la decisión libre y voluntaria de dar la propia vida en un acto supremo de amor cristiano, que supere el natural instinto de conservación, imitando a Cristo, que se ofreció al Padre por el mundo, en la cruz.

\section{La caridad como base}

Es claro, por lo tanto, que todas las vías hacia la santidad canonizada deben tener un denominador común que es la caridad, "vínculo de la perfección, plenitud de la ley [y] alma de la santidad". Tampoco el ofrecimiento de la vida puede, pues, prescindir de la perfección de la caridad, que, en este caso, sin embargo, no es el resultado de una prolongada, diligente y gozosa repetición de actos virtuosos, sino que es un único acto heroico que, por su radicalidad, irrevocabilidad y persistencia usque ad mortem, expresa plenamente la opción cristiana. Los teólogos, además, enseñan que, en virtud de la conexión entre las virtudes, donde se da un acto heroico de caridad no puede faltar un correspondiente acto de fe, esperanza, prudencia, fortaleza, etc.

Hay que decir también que el factor tiempo, es decir, la duración del ofrecimiento de la vida, tiene su relevancia. En efecto, si el acto heroico del ofrecimiento se prolongara años, podría al final entrar en el caso de las virtudes heroicas, que se convierten en tales no solo porque son expresión de comportamientos extraordinariamente perfectos, sino también porque prolongados en un tiempo notable, que la jurisprudencia canónica indica en una decena de años de práctica, en los casos ordinarios. Para delimitar este aspecto, el motu proprio habla muy oportunamente de "muerte en corto plazo", lo que no quiere decir que acontezca de modo inmediato, pero tampoco en un momento tan lejano que transforme el acto heroico en virtud heroica. En tal caso, cambiaría el supuesto.

En el caso en que se verificase la presencia simultánea del ofrecimiento heroico de la vida y el ejercicio heroico de las virtudes cristianas, es obvio que el iter jurídico preferido será el camino de las virtudes heroicas, que expresan con mayor plenitud la personalidad del Siervo de Dios, la santidad y la sinfonía de sus riquezas espirituales. Si fuera posible trazar una clasificación de los recorridos jurídicos para la constatación de la santidad canonizable, podríamos concluir poniendo el martirio en el primer puesto, las virtudes heroicas en el segundo, y el acto heroico del ofrecimiento de la vida hasta la muerte incluida en el tercero. Para concluir el razonamiento, podemos afirmar tranquilamente que quien ratifica su vida con un acto heroico de caridad puede ser considerado perfecto discípulo de Cristo y, como tal, merecedor de ser propuesto como modelo de vida cristiana, siempre que Dios mismo garantice dicha autenticidad y ejemplaridad mediante la fama de santidad, la prueba de los milagros y el juicio favorable de la suprema autoridad de la Iglesia.

\section{El caso del ofrecimiento de la vida}

El ofrecimiento de la vida usque ad mortem no constituía hasta ahora un caso en sí mismo, pero, si se daba, era incorporado, solo como un detalle, en el de las virtudes heroicas o bien en el del martirio. Es claro que esta incorporación no hacía justicia a una verdadera y, por muchos aspectos, conmovente expresión de santidad. 
Ya Benedicto XIV, el Magister, no excluía del honor a los altares a quienes habían dado la vida en un extremo acto de caridad, como, por ejemplo, la asistencia a los apestados que, provocando el contagio, se convertía en causa cierta de muerte.

Toda esta problemática comenzó a ser objeto de explícita reflexión por parte de la Congregación para las Causas de los Santos a partir del Congreso Ordinario del 24 de enero de 2014. El prefecto, Card. Angelo Amato, sometió la cuestión a la atención del Santo Padre Francisco en la audiencia del 7 de febrero siguiente. El Papa "aprobó y animó" al estudio de este nuevo supuesto, por lo que el dicasterio preparó una Positio peculiaris, con las contribuciones de cinco estudiosos de las causas de los santos: un biblista, un docente de teología dogmática, un especialista en teología espiritual, un jurista y un historiador.

El 2 de junio de 2016, la Congregación convocó sobre el argumento un Congreso Peculiar, compuesto por 15 expertos (10 consultores y 5 postuladores), diferentes de los de la Positio peculiaris. Presidió la reunión el obispo Mons. Enrico Dal Covolo, sobre todo en cualidad de postulador. La discusión se desarrolló en base al esquema de 5 cuestiones, comunicadas en la convocatoria del Congreso y formuladas así:

1. ¿El ofrecimiento de la vida, seguido de la muerte, puede ser juzgado como expresión de suprema y heroica imitación de Cristo?

2. ¿Cuáles características psicológicas y teológicas deberían tener el ofrecimiento de la vida para ser un acto heroico de caridad?

3. ¿El ofrecimiento de la vida debe madurar en el contexto de una consolidada vida cristiana o bien puede ser una decisión imprevista, es decir, sin una preparación remota?

4. ¿Es oportuno que el ofrecimiento de la vida sea un supuesto diferente del martirio y de las virtudes heroicas?

5. ¿El procedimiento jurídico para la eventual beatificación por viam vitae oblationis, además de la investigación diocesana super vita, virtutibus, oblatione vitae, fama sanctitatis debe comprender también la prueba de un milagro? (Relatio et Vota Congressus Peculiaris, 8).

A cada una de las preguntas contestaron por escrito los quince consultores y postuladores, confrontándose seguidamente en una reunión colegial (Congreso). Como es sabido, las conclusiones de los Congresos Peculiares de la Congregación para las Causas de los Santos son siempre importantes, porque expresan el motivado parecer de estudiosos y expertos que han examinado a fondo la materia. Sin embargo, su voto no es deliberativo ni vinculante.

En nuestro caso, la amplia y serena profundización del Congreso llevó a estas conclusiones: a) el ofrecimiento de la vida, seguido de la muerte, puede ser juzgado como expresión de suprema y heroica imitación de Cristo, como resulta en el Nuevo Testamento, en la Tradición de los mártires y de los confesores de la fe, en el Magisterio de los papas, en el Concilio Vaticano II y en la reflexión teológica, sobre todo a propósito de la caridad; b) el ofrecimiento de la vida, en la mayor parte de los casos, madura en un contexto de práctica de las virtudes cristianas; c) sobre la pregunta si el ofrecimiento de la vida debe ser un supuesto diferente del martirio y de las virtudes heroicas, la mayoría de los votos sostuvo la idea de configurar un supuesto distinto, mientras una minoría no lo consideró oportuno; d) sobre el procedimiento jurídico para la eventual beatificación por viam vitae oblationis, además de la investigación diocesana super vita, virtutibus, oblatione vitae, fama sanctitatis, la mayoría de los consultores y de los postuladores creyeron necesario, para la beatificación, un milagro formalmente aprobado.

Con estos pareceres, el 27 de septiembre de 2016, se llegó a la Sesión Plenaria de cardenales y obispos, miembros de la Congregación para las Causas de los Santos. También en esta sede, los varios aspectos de la cuestión fueron enfocados con profundidad de doctrina y amplitud de consideraciones pastorales. En conclusión, los cardenales y obispos dieron un parecer favorable a una nueva vía para la beatificación de quien ha ofrecido la vida con explícitas y reconocidas motivaciones cristianas. También se evidenció la necesidad 
de un milagro, formalmente aprobado, como confirmación divina del juicio humano sobre el ofrecimiento de la vida.

\section{El motu proprio Maiorem hac dilectionem}

Estas conclusiones fueron sometidas por la Congregación para las Causas de los Santos al Santo Padre Francisco en carta del 28 de noviembre de 2016 (Prot. num. VAR 7454/14). El 17 de enero de este año (2017) la Secretaría de Estado informaba al cardenal Amato que su Santidad "en fecha 10 de enero ha aprobado benevolente la propuesta de proceder a la beatificación de aquellos Siervos de Dios cuyo libre y voluntario ofrecimiento de la vida haya sido causa de su muerte". Se solicitaba también a la Congregación que "preparase el texto del pronunciamiento pontificio" para presentarlo a la definitiva aprobación del Santo Padre. El texto de tal pronunciamiento pontificio es ahora el motu proprio Maiorem hac dilectionem, firmado por el Papa Francisco.

\section{El ofrecimiento de la vida y el proceso jurídico}

Este documento pontificio precisa de modo muy oportuno en el artículo 2: a) ofrecimiento libre y voluntario de la vida y heroica aceptación propter caritatem de una muerte segura y a corto plazo; b) relación entre el ofrecimiento de la vida y la muerte prematura; c) el ejercicio, por lo menos en grado ordinario, de las virtudes cristianas antes del ofrecimiento de la vida y, después, hasta la muerte; d) existencia de la fama de santidad y de signos, al menos después de la muerte; e) necesidad del milagro para la beatificación, acontecido después de la muerte del Siervo de Dios y por su intercesión.

El artículo 3 del motu proprio añade el modo de regirse en la investigación canónica sobre el ofrecimiento de la vida y en la preparación del relativo dossier (Positio), que se somete a los consultores teólogos y cardenales: "La celebración de la investigación diocesana o eparquial y la relativa Positio están reguladas por la constitución apostólica Divinus perfectiones Magister, del 25 de enero de 1983 (Juan Pablo II, 1983) [...], y por las Normae servandae [...], del 7 de febrero del mismo año (Congregación para las Causas de los Santos, 1983)".

Esta normativa sobre el ofrecimiento de la vida también deberá ir de acuerdo, lógicamente, con la instrucción Sanctorum Mater del 17 de mayo de 2007 (Congregación para las Causas de los Santos, 2007), que pretende facilitar la correcta aplicación de la legislación de 1983. En fin, el motu proprio ha decidido que el dubium, es decir, el objeto de la verificación de las causas sobre el ofrecimiento de la vida, sea formulado en el siguiente modo: "An constet de heroica oblatione vitae usque ad mortem propter caritatem necnon de virtutibus christianis, saltem in gradu ordinario, in casu et ad effectum de quo agitur" ${ }^{\text {[\$\$\$\$] }}$. El Santo Padre dispuso al mismo tiempo que este acto legislativo suyo fuese promulgado en L'Osservatore Romano y que entrase en vigor el mismo día de su publicación.

\section{Conclusión}

Con este pronunciamiento la doctrina sobre la santidad cristiana canonizable y el procedimiento tradicional de la Iglesia para la beatificación de los Siervos de Dios no solamente no han sido alterados, sino que han sido enriquecidos con nuevos horizontes y oportunidades para la edificación del pueblo de Dios, que en sus santos ve el rostro de Dios, la presencia de Dios en la historia y la ejemplar actuación del Evangelio. 


\section{Nueva vía para la santidad[*****]}

Entrevista de Nicola Gori al cardenal Angelo Amato, prefecto de la Congregación para las Causas de los Santos

Fray Cristoforo, el capuchino que eligió servir a los apestados aun arriesgando la vida, es una imagen elocuente y a todos bien conocida del ofrecimiento de la vida para servir a los demás en la caridad. El genio literario de Alessandro Manzoni, autor que gusta mucho al Papa Francisco, puede ayudar a comprender el significado del motu proprio Maiorem hac dilectionem, documento que ha abierto una cuarta vía para las causas de beatificación y canonización. Esto lo explica el cardenal Angelo Amato, prefecto de la Congregación para las Causas de los Santos, en esta entrevista concedida a L'Osservatore Romano.

El 11 de julio ha sido publicado el motu propriosobre el ofrecimiento de la vida en las causas de los santos. ¿Dequése trata?

El incipit hace referencia a la palabra de Jesús: "Nadie tiene un amor más grande que quien da su vida por sus amigos" (Jn, 15,13). Sin duda, todos los santos han vivido plenamente el don de la caridad, ofreciendo su vida al Señor y al prójimo sea en el ejercicio de las virtudes cristianas sea en la defensa de la propia fe frente a los perseguidores, que desde el principio han combatido contra el Evangelio. Por eso las causas de beatificación y canonización siguen generalmente dos itinerarios: la [de la] verificación o la heroicidad de las virtudes (los llamados confesores, como, por ejemplo, Pío de Pietrelcina o Madre Teresa de Calcuta) o la de la muerte in odium fidei (para los mártires, como, por ejemplo, los ochocientos santos mártires de Otranto o el adolescente mexicano José Sánchez del Río).

El motu proprio, además de las dos clásicas vias, ¿propone una tercera?

Sí. Lo dice el primer artículo del motu proprio: "El ofrecimiento de la vida es un nuevo caso del iter de beatificación y canonización, distinto del caso de martirio y de heroicidad de las virtudes".

El ofrecimiento de la vida está siempre presente en las investigaciones. ¿Qué distingue, entonces, de las otras dos vias a este nuevo supuesto?

Son cinco los requisitos que dan originalidad a esta tercera vía. Ante todo, el ofrecimiento de la vida debe ser libre y voluntario en la aceptación propter caritatem de una muerte cierta y a corto plazo. Tiene que darse, pues es el segundo requisito, [una] conexión estrecha entre el ofrecimiento de la vida y la muerte prematura. En tercer lugar, se requiere el ejercicio de las virtudes cristianas, si no en grado heroico, al menos en grado ordinario hasta la muerte. En cuarto lugar, tiene que estar presente la fama de santidad y de signos, al menos después de la muerte.

Como para el martirio, ¿también en esta vía está prevista la exención del milagro para la beatificación?

No. El quinto requisito, en efecto, se refiere precisamente a la necesidad del milagro para la beatificación, acontecido después de la muerte del Siervo de Dios y por su intercesión. Al contrario de como está previsto para la causa sobre el martirio, que no requiere el milagro para la beatificación sino solo para la canonización, en este tercer supuesto el milagro se necesita como en las causas sobre la heroicidad de las virtudes. El milagro será siempre el sigilo de Dios también en esta tercera vía. En conclusión, pues, la Positio -es decir, el dossier sobre el ofrecimiento de la vida- debe responder a la duda si, en el caso del que se trata, consta ya sea del ofrecimiento de la vida hasta la muerte por caridad o ya de la presencia de las virtudes cristianas, al menos en grado ordinario.

¿El motu proprio presenta otras indicaciones?

Sí, hace referencia a los actores, ya sea para iniciar la eventual causa en fase diocesana o eparquial, ya sea para la elaboración de la Positio en fase romana. En referencia a la fase diocesana o eparquial es bueno seguir las preciosas indicaciones contenidas en la instrucción Sanctorum Mater, publicada por la Congregación para las Causas de los Santos en 2007.

¿El ofrecimiento de la vida es una tercera o una cuarta vía? 
Hay que entenderse. Como ya hemos mencionado, tradicionalmente las vías para la canonización son fundamentalmente dos: la vía del martirio, supremo testimonio de la caridad, y la vía de las virtudes heroicas, suprema imitación de Cristo. Hay otra vía, más rara y menos conocida, que es la vía de los llamados casus excepti. Esa significa el reconocimiento de un culto antiguo, es decir, sucesivo al pontificado de Alejandro III (muerto en 1181) y anterior a 1534, como estableció Urbano VIII (1623-1644), uno de los grandes legisladores de las causas de los santos. La confirmación del culto antiguo se llama también beatificación equivalente. Si llamamos tercera vía a la beatificación equivalente, el ofrecimiento de la vida, después de cuanto hemos dicho, se puede llamar con toda razón la cuarta vía. Esta presenta analogías con el martirio y con las virtudes, se diferencia del martirio porque no nos encontramos con un perseguidor que mata por odio a la fe. Es diferente de la vía sobre las virtudes porque no requiere, de por sí, del ejercicio prolongado de las virtudes en grado heroico. Hay muchos casos concretos que han motivado la larga y meditada reflexión de la Congregación para las Causas de los Santos sobre esta nueva vía. Se espera ahora el discernimiento de los obispos o de los eparcas para activar en concreto este nuevo supuesto. Se trata, de todos modos, de evidenciar la múltiple presencia de la santidad en la vida de la Iglesia.

\section{El amor más grande: dar la vida por los hermanos $[\dagger \dagger \dagger \dagger \dagger]$}

\section{Marcello Bartolucci}

\section{La buena salud de las causas de los santos}

Las causas de los santos son un sector de la vida de la Iglesia que goza de buena salud, pues en casi cincuenta años, desde el Concilio Vaticano II (1962-1965) hasta hoy, no solo el número de las causas, de santos y beatos, se ha visto multiplicado e internacionalizado, sino que también los procedimientos jurídicos para la beatificación y la canonización se han actualizado repetidamente, con la explícita finalidad de agilizar y afinar los instrumentos de conocimiento y de juicio, que, efectivamente, se habían recargado desde la época barroca.

La primera intervención legislativa posconciliar, cuyos efectos duran aún, fue el motu proprio Sanctitas clarior del beato Pablo VI (19 de marzo de 1969), que unificó el proceso ordinario sobre la fama de santidad y el proceso apostólico sobre las virtudes en especie en un solo proceso llamado cognicional, que corresponde a la actual investigación diocesana. Con esta deliberación, en cierto modo deseada por el Concilio ${ }^{[\neq \neq \neq \neq \neq 1]}$, se aceleraban los tiempos de las investigaciones sobre la vida y la santidad de los Siervos de Dios y se mejoraba la cualidad de las pruebas testificales, ya que se recogían en un tiempo más cercano a los hechos. En el mismo año se instituían dos nuevos dicasterios, uno para el Culto Divino y otro para las causas de los santos (Pablo VI, 1969), que ocupaban el puesto de la antigua y benemérita Sagrada Congregación de Ritos, instituída por Sixto V el 22 de enero de 1588, cuando organizó toda la Curia con la bula Inmensa Aeterni Dei.

Después de años de derogaciones, dispensas, facultades especiales, retoques normativos y diferentes comisiones de estudio (incluso cardenalicias) ${ }^{[\$ \$ \varsigma \$ \$]}$, se llegó a la audaz constitución apostólica Divinus perfectionis Magister (Juan Pablo II, 1983) y a las respectivas Normae servandae ab Episcopis (Congregación para las Causas de los Santos, 1983), con las cuales san Juan Pablo II reorganizó toda la normativa de las causas de los santos, para lo que privilegió el método histórico por encima del jurídico. Como ocurre a menudo en las reformas radicales, también en esta se perdieron partes importantes del pasado, por ejemplo, el papel del censor-objetor (las famosas animadversiones) del promotor de la fe y el debate in scriptis entre el mismo promotor y el abogado de la causa. En compensación, la investigación documental fue oportunamente ampliada y valorizada, con lo que se dio lugar a Positiones más substanciosas y científicas.

Benedicto XVI, el 29 de septiembre de 2005, establecía que el rito de las beatificaciones se llevase a cabo en la diócesis que había promovido la causa del nuevo beato y que normalmente fuese el prefecto de la 
Congregación para las Causas de los Santos quien presidiese la ceremonia ${ }^{[* * * * *]}$. El mismo Pontífice el 22 de febrero de 2007 aprobaba la Instrucción Sanctorum Mater (Congregación para las Causas de los Santos, 2007), que era promulgada el 17 de mayo sucesivo. El documento se ha revelado como una apreciada guía práctica para la correcta aplicación de las Normae servandae de 1983 (Congregación para las Causas de los Santos, 1983). El 3 de julio de 2009, Benedicto XVI decidió aumentar de 5 a 7 el número de peritos de la Consulta Médica, además estableció que las conclusiones de las sesiones serían válidas solo si eran aprobadas por la mayoría de dos tercios $(5 / 7,4 / 6)^{[+t+t+]}$. El 4 de marzo de 2016, el Papa Francisco aprobaba las Normas sobre la administración de los bienes de las causas de beatificación y canonización ${ }^{[\neq \neq \neq \neq \neq \neq \neq]}$y el 24 de agosto siguiente veía la luz el nuevo Reglamento de la Consulta Médica ${ }^{[\$ \varsigma s \$ s]}$; por último, el 29 de junio de 2017 le tocó el turno a la Instrucción sobre las Reliquias en la Iglesia ${ }^{[* * * * *]}$.

El 11 de julio de 2017, fue promulgado, al fin, el motu proprio Maiorem hac dilectionem con el que Papa Francisco abrió la posibilidad de beatificación de "aquellos cristianos que, siguiendo más de cerca las huellas y las enseñanzas del Señor Jesús, han ofrecido voluntaria y libremente la vida por los demás y han perseverado hasta la muerte en este propósito" (Francisco, 2017). El documento, del que ahora hablamos, no ha sido pensado para inaugurar nuevos procedimientos y formalidades jurídicas, sino simplemente para ampliar los modelos de santidad beatificable que, hasta hoy, incluían únicamente en los mártires y en los héroes de las virtudes cristianas. Esto quiere decir que todo lo que concierne al procedimiento de la investigación diocesana sobre el ofrecimiento de la vida y la relativa fase romana de juicio seguirán en todo y para toda la constitución apostólica Divinus perfectionis Magister y las Normae servandae ab Episcopis, tal como dispone explícitamente el artículo 3 del motu proprio. Si bien no se menciona expresamente, puesto que no es un texto legislativo sino aplicativo, la Instrucción Sanctorum Mater conserva su plena validez también en las investigaciones diocesanas de este supuesto.

\section{¿Por qué una nueva vía para la beatificación?}

Una nueva vía porque al ofrecimiento de la vida no se le había dado aún una atención proporcionada a su relevancia en el campo de la santidad beatificable. En la base del nuevo camino para la beatificación hay que poner una pregunta de naturaleza teológica: “¿El ofrecimiento de la vida, seguido de la muerte, puede ser juzgado como expresión de suprema y heroica imitación de Cristo?" [t+t+t+t]. Insisto en el hecho de que hasta el motu proprio las únicas manifestaciones de heroísmo, útiles para la beatificación, eran el martirio y las virtudes heroicas.

Ahora se reconoce que al ofrecimiento de la vida también se le puede atribuir la misma dignidad; de ahora en adelante el ofrecimiento de la vida es una vía legítima y suficiente para la beatificación formal, siempre que el ofrecimiento sea libre, voluntario, motivado por la fe y traducido en un "acto" de amor total, heroico, irreversible, es decir, hasta el sacrificio extremo de sí mismo por los demás.

Quien actúa de esta manera ha recibido del cielo la gracia de expresar voluntariamente una perfecta imitación de Cristo, que conscientemente ha dado la vida por el mundo en un acto de caridad infinita. El cristiano "beatificable", por lo tanto, no es un creyente ordinario, aunque coherente, fervoroso, comprometido en el servicio a Dios y al prójimo. Así, el "beatificable" es mucho más; por la gracia, este es un "héroe" en el amor y fidelidad a Cristo, porque le sigue en la vía del supremo don de sí, sin interrupciones, sin quejas, sin reservas, sino con una consciente y libre determinación de caridad heroica, tan apasionante que supera los instintos naturales de conservación. Sin embargo, quien se ofrece puede tomar todas las precauciones para tutelar la propia vida, aun perseverando en la radicalidad de su ofrecimiento. Igualmente, el potencial mártir está autorizado a intentar poner a salvo su propia vida. 
La frase evangélica "nadie tiene un amor más grande que quien da su vida por sus amigos" (Jn 15,13) es el incipit del motu proprio y expresa exactamente lo que Jesús ha hecho y que los discípulos intentan hacer cuando, empujados por la caridad, entregan físicamente la vida por los demás.

Es necesario tener bien presente que hablamos de "acto heroico", de decisión heroica y no de "virtud heroica" en el sentido entendido por el procedimiento de las causas de los santos. Sabemos que la virtud heroica existe cuando el comportamiento virtuoso se convierte en un modo habitual de actuar, durante un largo tiempo, también en circunstancias difíciles. El acto heroico del ofrecimiento, de breve duración, no subsiste, sin embargo, solo en el momento de la decisión se mantiene, puesto que, necesariamente, debe prolongarse hasta su consumación: usque ad mortem. Por lo tanto, en el ofrecimiento de sí se da un verdadero heroísmo de breve duración (muerte "a corto plazo"), pero no menos arduo o de menor intensidad respecto al de las virtudes heroicas y al del martirio. Durante el tiempo que precede al ofrecimiento, normalmente se requiere una seria y coherente vida cristiana, aunque no heroica (virtud, al menos, ordinaria). También se debe considerar el caso particular del pecador que repentinamente cambia de vida y enseguida se ofrece con un acto heroico usque ad mortem, por lo que merece también el reconocimiento de la Iglesia. Después de la decisión de ofrecerse, sería humanamente incomprensible la perseverancia usque ad mortem si no hubiese una fuerte determinación sobrenatural, inspirada por la fe-esperanza-caridad en grado eminente. La expresión "acto heroico", por lo tanto, puede indicar un comportamiento extraordinario de una duración temporal (hasta la muerte) que deberá, sin embargo, ser más breve respecto a la requerida para el heroísmo de las virtudes (los famosos diez años).

El hecho de restringir la santidad beatificable a un acto heroico de caridad ¿no empobrece la santidad tradicional que se pide a los candidatos al honor de los altares? El ofrecimiento de la vida, manifestado en un acto heroico definitivo que se prolunga coherente y "heroicamente" hasta la muerte, es una verdadera y completa imitación de Cristo, y, de igual forma, es en los mártires, cuyo heroísmo no se da en el prolongado ejercicio de las virtudes, sino que se concentra en eventos y comportamientos de breve duración y de altísima calidad moral.

Hay otro aspecto que no se debe descuidar en la valoración del heroísmo de quien ofrece la vida: la atención de quien observa y evalúa va dirigida, obviamente, en primer lugar, al acto supremo de caridad, pero no se deberá olvidar que existe una conexión orgánica entre las diferentes virtudes; por lo tanto, la caridad heroica, cuando existe, no puede ir separada de las otras virtudes cristianas (Benedicto XIV, 2015). La caridad no vive sola, sino que tiene necesidad de la fe y de la esperanza. La vida teologal "es vida de caridad, por la fe, en la esperanza" (Cozzoli, 2010). La caridad sintetiza todo el vivir cristiano, en otras palabras, "las virtudes convergen en la caridad como en su centro y en su vértice" (Cozzoli, 2010).

En el supuesto que examinamos, de todas formas, no se insistirá suficientemente sobre la necesidad de probar jurídicamente que el ofrecimiento de sí mismo es un verdadero "acto heroico de caridad" o un usque ad mortem. En efecto, es precisamente este acto supremo, radical y definitivo el que identifica al fiel con Cristo crucificado y que, además, justifica una cuarta vía para la beatificación. Sobre este punto, el motu proprio es explícito:

Es cierto que el ofrecimiento heroico de la vida, sugerido y sostenido por la caridad, expresa una imitación verdadera, completa y ejemplar de Cristo y, por tanto, es merecedor de la admiración que la comunidad de los fieles suele reservar a los que han aceptado voluntariamente el martirio de sangre o han ejercido heroicamente las virtudes cristianas. (Francisco, 2017)

En estas pocas palabras se encuentra la substancia teológica del motu proprio, cuya primera consecuencia jurídica es el artículo 1, que afirma: "El ofrecimiento de la vida es un nuevo caso del iter de beatificación y canonización, distinto del caso de martirio y de heroicidad de las virtudes". Alguien que ha participado en los trabajos de la Congregación para las Causas de los Santos sobre esta materia ha escrito que la mayoría de los 15 consultores teólogos y postuladores, reunidos en el Congreso Peculiar del 2 de enero de 2016, "sostuvo la idea de configurar un supuesto distinto, mientras que una minoría no lo consideró oportuno" (Bartolucci, 
2017b). La misma fuente añade que los padres cardenales y obispos, en la siguiente Sesión Plenaria del 27 de septiembre de 2016, tras haber superado todas las perplejidades "dieron un voto favorable a una nueva vía para la beatificación de quien ha ofrecido la vida por explícitas y reconocidas motivaciones cristianas”. Todos estos pareceres han preparado el terreno a la decisión pontificia, que ahora es ley para toda la Iglesia.

\section{¿Cómo era antes del motu proprio?}

Antes del motu proprio el ofrecimiento de la vida, si se daba, era un "momento", un "detalle" del supuesto del martirio o del supuesto de las virtudes heroicas. Si el ofrecimiento hubiese sido reconocido como un acto heroico por sí mismo, no sería suficiente para configurar una santidad heroica beatificable. Ahora, después de las múltiples profundizaciones y, sobre todo, después de la decisión del Santo Padre se ha llegado a la conclusión de que el acto heroico del ofrecimiento de sí, usque ad mortem, asemeja plenamente el discípulo al Maestro y que, de consecuencia, las vías jurídicas del martirio y de las virtudes heroicas no son apropiadas para este género de heroico testimonio.

\section{La vía del martirio}

El ofrecimiento de la vida no es martirio y no es exacto llamarlo "martirio de caridad". Por esta razón es necesario hacer una premisa: todos saben que los procedimientos más antiguos para la proclamación de los santos son los de los mártires, que iniciaron prácticamente en el tiempo apostólico (san Esteban), pero enseguida surgieron los aspectos esenciales del martirio y del perfecto imitador de Cristo. Se ha escrito con acierto que "los mártires son los primeros santos del cristianismo" (Misztal, 2005), estos son inmediatamente honrados por la comunidad cristiana como los más perfectos imitadores de Jesús. Benedicto XIV ha definido el martirio como "suportación y tolerancia voluntaria de la muerte por la fe en Cristo o por otro acto de virtud referido a Dios" (Benedicto XIV, 2015, n.. 1). El Vaticano II ha hablado del martirio como el "máximo testimonio de amor ante todos, especialmente ante los perseguidores [...], suprema prueba de la caridad” (Pablo VI, 1994, 42). En estas expresiones, teológicamente preciosas para alguien, podría entrar también el ofrecimiento de la vida.

Pero el concepto consolidado de martirio y la normativa vigente no lo permiten, pues dicen, en efecto, que el verdadero martirio se da cuando aparecen al mismo tiempo tres elementos: 1) un cristiano que consciente y voluntariamente rechaza renegar a Cristo y que, con tal de permanecer fiel a su credo cristiano, prefiere sufrir una muerte prematura y violenta; 2 ) un perseguidor, talmente intolerante y violento contra la fe u otras virtudes cristianas, que lleva a cabo actos concretos y desproporcionados para eliminar físicamente a quien se adhiere a Cristo, y 3) el comportamiento del cristiano (la víctima) durante la persecución y, especialmente, en proximidad de la muerte, que es conforme a la caridad, la paciencia y la mansedumbre de Jesús Crucificado que perdona a sus asesinos. En el pasado y en el presente, el perfecto mártir cristiano se ha comportado y se comporta así, por lo que: quien obra en el ámbito de las causas de los santos está convencido de que no debe modificarse esta visión del martirio, acogida desde siempre por el sentir común de la Iglesia. Es evidente que quien ofrece espontáneamente la propia vida, propter caritatem, se parece parcialmente al mártir que se sacrifica a sí mismo para no traicionar a Cristo, pero se diferencia de él porque en el caso del ofrecimiento de la vida está ausente totalmente la figura del perseguidor in odium fidei.

Llegados a este punto, es oportuno mencionar una cuestión que Benedicto XIV aborda expresamente en su obra (Benedicto XIV, 2015) y que puede tocar también, en un cierto sentido, al supuesto del ofrecimiento de la vida. Se trata del llamado martyrium per pestem, es decir, del martirio de quienes contraen la peste mientras socorren por caridad a los apestados y perecen contagiados por el mismo mal. ¿Esta muerte prevista y no evitada, que es casi buscada, puede ser considerada martirio? En tiempos de Benedicto XIV algunos 
pensaban que sí, pero la respuesta del Magister es negativa, pues falta el perseguidor. En efecto, la tesis del martyrium perpestem, sostenida por el teólogo francés Teófilo Raynaud (1583-1663), fue condenada en 1646 por la Congregación de los Ritos (Benedicto XIV, 2015). El muy ilustre doctor conventual, cardenal Lorenzo Brancati di Lauria (1612-1693), citado por el mismo Benedicto XIV como un excelente autor (Benedicto XIV, 2015), enseña que quien muere a causa de la asistencia a los apestados "se puede llamar mártir en sentido lato, sin embargo, no se puede llamar mártir en sentido estricto y según la praxis de la Iglesia” (Benedicto XIV, 2015). Este era también el pensamiento de Ludovico Antonio Muratori y de otros.

En 1992, el padre Benito Gangoiti, O. P., decano de la Facultad de Derecho Canónico de la Pontificia Universidad Santo Tomás de Aquino en Roma y consultor de la Congregación para las Causas de los Santos, reanudaba este tema en un estudio titulado Verso un sensus plenior del martirio (1992), en el cual defendía que: 1) el martirio, en sentido estricto, es el clásico en el que un perseguidor voluntario (hombre) mata por odium fidei; 2) en sentido amplio (plenior), el martirio también es aquel en el que el perseguidor no es una persona, sino "un evento-causa necesaria de la muerte" (por ejemplo peste o lepra, etc.). Como se ha dicho, a esta hipótesis de trabajo contestó negativamente la Congregación, Benedicto XIV y el cardenal Brancati, entre otros. Hoy nadie sigue seriamente esta tesis. El llamado martyrium per pestem, por lo tanto, no es martirio, sino que podría entrar fácilmente en el supuesto del ofrecimiento de la vida usque ad mortem, lo que no es menos meritorio.

\section{La vía de las virtudes heroicas}

El ofrecimiento de la vida tiene relación solo parcialmente con el supuesto de las virtudes heroicas. La pregunta sobre cuál era la santidad canonizable, excluida la de los mártires (ya clara y definida desde tiempos de san Esteban), se precisó a lo largo de un milenio del siglo IV, cuando comenzó a surgir la nueva categoría de los confesores (ascetas, monjes, obispos, vírgenes y viudas, etc.), elevados al culto no a causa del martirio de sangre, sino por el "martirio blanco de la santidad", es decir, de una vida radicalmente conforme al Evangelio. Ya en el siglo II aparece, en el lenguaje de la Iglesia, la clara distinción entre mártir y confesor (Cesaréia, 2008, V, 2- 2): así, el primero es quien derrama la sangre por Cristo y el segundo es quien se declara abiertamente (confessor) a favor de Cristo, ha sufrido por él, pero no le ha sido quitada la vida a motivo de la fe (Benedicto XIV, 2010). Resulta, de todas formas, que los dos términos serían usados de manera indiferente incluso por mucho tiempo (por ejemplo, en Tertuliano, Orígenes y Cipriano, etc.).

Después de la paz constantiniana (año 313), poco a poco entra en el catálogo de los santos el ejército de los confesores en el sentido actual (Benedicto XIV, 2010), es decir, de aquellos cristianos que han vivido el Evangelio de manera ejemplar y han muerto por muerte natural. Entre los primeros confesores se recuerdan san Eustorgio (331 d. C.), san Atanasio (373 d. C.) y san Martín (397 d. C.), etc. Todos estos santos, y los que les seguirán en el tiempo, han entrado en el catálogo gracias a su santidad superior y a su reconocido poder de intercesión ante Dios mediante la realización de milagros.

$\mathrm{Al}$ principio, la santidad heroica (la de los confesores) era examinada no según un esquema rígido de investigación sobre cada una de las virtudes (como se hace hoy), sino según las manifestaciones prevalentes del Espíritu, quienes conceden a algunos el espíritu ascético, a otros el poder taumaturgo, a otros la virginidad y a otros el poder contra el maligno, etc. Obviamente, el modelo supremo para cada tipo de santidad era siempre "Cristo pobre, humilde y cargado con la Cruz" (Pablo VI, 1964, 42); este era imitado, sin embargo, con acentuaciones diferentes en cada santo, en cada época y en cada cultura.

Hoy la investigación sobre la santidad de la vida se ha afinado y se rige por un esquema irrenunciable para todos los siervos de Dios "no mártires": se trata del esquema de las virtudes teologales (fe, esperanza y caridad), cardinales (prudencia, justicia, fortaleza y templanza) y anejas (obediencia, pobreza, castidad y humildad). 
Este esquema no aparece en su forma rigurosa sino en el proceso de san Buenaventura en 1482. Antes de esta época era suficiente un ramillete de virtudes cristianas y se decía, de san Amancio por ejemplo, que fue perfecto en la humildad, disponible en la misericordia, de una incansable liberalidad, de una santa sencillez, loable por las vigilias, perseverante. (Thils y Bussi, 1960, p. 31)

Ahora, desde hace siglos, todo el trabajo teológico y procesal de las causas de los santos busca demostrar que el candidato a la beatificación tiene un poder de intercesión ante Dios y que ha practicado las virtudes en grado heroico. La virtud heroica es el mejor resultado visible y documentable de la colaboración entre la gracia divina y la libertad humana que, remando concordemente hacia el mismo puerto, conducen a una extraordinaria y ejemplar semejanza con Cristo. La virtud heroica imprime los rasgos de Cristo, al igual que el martirio y el ofrecimiento de la vida, sin embargo, la criatura nunca será igual al Creador (san Agustín). "Heroica" no quiere decir que la virtud se expresa en comportamientos de super-hombre, sino que significa extraordinariamente fiel a Cristo, al Evangelio y a la Iglesia, y que es practicada en situaciones arduas, con buena voluntad (expedite), con prontitud (prompte), con alegría (delectabiliter), de manera que supera el modo común de actuar de los buenos cristianos (supra humanum modum) y por un fin sobrenatural.

Cuando hablamos de virtud es claro que nos referimos a un modo habitual de ser y de actuar. La virtud, en efecto, es un habitus que se forma con la repetición de actos en el tiempo. Según la praxis de la Congregación, el habitus es verdadero y creíble cuando se manifiesta de modo ininterrumpido durante un largo periodo que se cuantifica en una decena de años en el caso de los adultos. El discurso es, naturalmente, diferente para los niños y para los jóvenes, cuyo heroísmo es siempre relativo en relación a la edad (Sesión Plenaria de 1981). Todo esto nos dice que el ofrecimiento de la vida, que consiste esencialmente en un "acto heroico" de caridad, aunque prolongado en el tiempo ("muerte a corto plazo"), no puede entrar en el supuesto de las virtudes heroicas, pues, para serlo debe caracterizarse por la diuturnitas de varios años. Esto conlleva que los casos en los que el acto heroico del ofrecimiento tiene que prolongarse y conducir a la muerte en un espacio de tiempo notablemente largo entrarían en el supuesto de las virtudes heroicas, cuya vía, cuando es posible, es preferible respecto a la del ofrecimiento de la vida.

\section{¿Qué ofrecimiento de la vida?}

No cualquier ofrecimiento de la vida es válido para la beatificación, sino solo aquel que corresponde a los cinco criterios indicados en el artículo 2 del motu propio.

\section{Primer criterio: ofrecimiento libre y voluntario de la vida, y heroica aceptación propter caritatem de una muerte segura y a corto plazo}

Aquí no se trata de aquel género de ofrecimiento "ad omnia" que exigen, más o menos formalmente, algunos institutos religiosos o que emiten fervientes cristianos que se entregan en las manos de Dios, quienes están prontos también a morir por la fe u otra virtud cristiana, si eventualmente les fuese pedido. Aquí ni siquiera se trata de aquel ofrecimiento práctico de sí que comporta cotidianamente un progresivo deterioramiento de la salud hasta incidir de hecho sobre la duración de la vida. Este género de ofrecimiento podría pertenecer al ámbito de las virtudes, en el que la diuturnitas es un componente necesario.

No parece, además, que el motu proprio se refiera a un ofrecimiento de sí, seguramente heroico pero jurídicamente no verificable, que algunas almas generosas emiten por una finalidad espiritual (por ejemplo para obtener vocaciones, conversiones, reparar los pecados, unir a los cristianos o promover la paz entre los pueblos, etc.) y a la que sigue realmente una muerte prematura. ¿Quién puede garantizar con pruebas objetivas y jurídicas que en estos casos la muerte esté físicamente vinculada al ofrecimiento? El nexo moral e invisible en nuestro caso no es suficiente, como no es suficiente una muerte accidental, imprevista y casual que implica a 
quien está realizando una obra de caridad, no especialmente peligrosa (por ejemplo un accidente de carretera que causa la muerte de un sacerdote durante su ministerio).

El supuesto considerado en el motu proprio se refiere a un ofrecimiento personal, libre (no requerido por una norma), consciente, voluntario y específico que el fiel, tocado por la gracia, hace de propia iniciativa para ir física y visiblemente en ayuda del prójimo necesitado de una concreta y bien definida cercanía, y que, en caso de faltarle, sufriría de graves daños. En este supuesto podrían entrar aquellos cristianos (obispos, misioneros, párrocos, médicos, educadores y militares, etc.) que se ofrecen espontáneamente en un acto de caridad personal o social tan arriesgado que se prospecta el sacrificio de la vida. Normalmente se tratará de una certeza no absoluta sino moral, es decir, de aquella que excluye toda duda fundada y razonable. Si quien ofrece su vida conscientemente continúa de todas formas en el don de sí mismo a pesar del riesgo y, de hecho, muere perseverando hasta el final en el acto de caridad (evangelización, ministerio, asistencia espiritual o corporal, etc.), se puede hablar con fundamento de un auténtico ofrecimiento de la vida en el sentido entendido por el motu proprio.

En esta nueva vía de beatificación se tendrá que considerar caso por caso si se puede incluir también el testimonio de algunas gestantes cristianas que, para no dañar a la incolumnidad del feto, rechazan conscientemente tratamientos absolutamente necesarios para sobrevivir y se encaminan hacia una muerte segura y prematura. Es normal que en este género de ofrecimiento un papel de primer orden se deba al natural instinto maternal, pero para una causa de beatificación debe resultar, como motivación prevalente, la visión cristiana de la vida y la voluntad de cumplir propter caritatem un heroico ofrecimiento de sí en favor del no nacido. Igualmente heroico parece el ofrecimiento de quien toma libremente el puesto de un condenado a muerte; de quien explota al desactivar un dispositivo peligroso para la comunidad; de quien muere a causa de una arriesgada operación de rescate, y particularmente delicado es el caso de los capellanes militares en tiempo de guerra, los cuales, como todos, intentan evitar la muerte a menos que, voluntariamente, por razones pastorales gravísimas y urgentes, se enfrenten a situaciones seguramente mortales, como por ejemplo el capellán que, en lugar de ponerse a salvo, continúa asistiendo a un moribundo bajo el fuego enemigo hasta llegar a morir. En este caso se puede hablar de verdadero ofrecimiento de la vida.

Los casos podrían ser muchos, pero en todo caso los elementos esenciales son siempre los mismos: libertad, voluntariedad, consciencia, caridad cristiana, nexo físico entre el ofrecimiento y la muerte.

El motivo que empuja a quien se ofrece a actuar de ese modo debe ser jurídicamente documentable y evidentemente inspirado por la fe; además, este debe estar centrado en la caridad para con el prójimo, de modo que la motivación religiosa resulte moralmente segura y primaria respecto a otras eventuales motivaciones concomitantes. La investigación canónica sobre este punto será rigurosa y no podrá dar por descontado aquello que debe ser probado.

\section{Segundo criterio: nexo entre el ofrecimiento de la vida y la muerte prematura}

El nexo es más que una sucesión cronológica de eventos: el post hoc no siempre coincide con el propter hoc. En nuestro caso significa, sobre todo, que la muerte no habría acontecido si quien se ofrece no hubiese implicado voluntaria, física y visiblemente su vida en un acto heroico de caridad. ¿La muerte, pues, sería un efecto previsto y también querido?, ¿se puede hablar entonces de suicidio?

Este argumento fue abordado por el tercer consultor del Congreso peculiar del 2 de junio de 2016, el cual concluye escribiendo que "la causa directa de la muerte" es el peligro objetivo (por ejemplo, la peste o lepra), mientras que "la causa indirecta" es el ofrecimiento de sí. Si la oblación fuese causa directa de la muerte,

nos encontraríamos ante un suicidio, que es siempre pecado ${ }^{[\neq \neq \neq \neq \neq \neq \neq]}$. A parte de las formales verbales, que tienen siempre su importancia, la sustancia es que en nuestro caso quien se ofrece quiere cumplir consciente y directamente un acto de caridad que, sin embargo, es también mortal. El fin principal de quien se ofrece 
es el acto de caridad y el bien que de ello se deriva, mas no la muerte que de hecho resulta. Quien curaba a los apestados lo hacía para ayudar a los demás, no para destruirse a sí mismo. Si el fin principal de la obra no hubiese sido el acto de caridad sino la autodestrucción, nos moveríamos en el terreno de la inmoralidad.

\section{Tercer criterio: ejercicio, al menos en grado ordinario, de las virtudes cristianas antes del ofrecimiento de la vida y, después, hasta la muerte}

El motu proprio, en el artículo 4, al definir el dubium al que debe responder la Positio, recita: An constet de beroica oblatione vitae [...] propter caritatem necnon de virtutibus christianis saltem in gradu ordinario. El texto deja entender que el objeto de la investigación canónica es doble así la atención principal recaiga sobre el acto heroico de caridad (desde el inicio hasta el final) y, después, sobre cada una de las virtudes cristianas practicadas por el Siervo de Dios saltem in gradu ordinario. Una diligente investigación procesal sobre las virtudes en especie es, por tanto, inevitable, y sigue, si es posible, el esquema tradicional de la investigación canónica (virtudes teologales, cardinales y anejas). Las virtudes, practicadas entre el ofrecimiento de sí y la muerte (normalmente por un breve periodo de tiempo), podrían resultar también más que ordinarias, es decir, excelentes, extraordinarias y brillantes, pero si falta la diuturnitas, no podemos considerarlas técnicamente hábitos heroicos en el sentido requerido para las causas super virtutibus. Es normal que desde el momento del ofrecimiento de sí el nivel de las virtudes alcance un grado particularmente alto y ejemplar, es más, heroico a motivo de la conexión existente entre las virtudes, pero probablemente esta heroicidad no siempre será demostrable con pruebas adecuadas, especialmente cuando los tiempos son particularmente rápidos.

De todos modos, es necesario verificar la existencia de una sólida y convincente estructura cristiana de la vida también en el periodo precedente al ofrecimiento, de manera que quede moralmente fundamentada la motivación evangélica del ofrecimiento mismo. Por ser tan extremo, radical e irreversible, el ofrecimiento no puede tener sus orígenes en una fe y una práctica cristiana mediocre y tibia, a menos que no se trate de una conversión repentina que alcanza, del mismo modo repentino, el heroísmo de la caridad. Para ser heroico el ofrecimiento de sí deberá ir acompañado no solo de las virtudes teologales, sino también de prudencia, fortaleza, justicia y templanza para que el acto de caridad sea moralmente loable y ejemplar en todo. En concreto, por ejemplo, es necesario que el ofrecimiento heroico no sea determinado por la impulsividad, por la infatuación, por la exaltación, por el exhibicionismo o por la ostentación, etc. Quien se ofrece deberá, además, saber anticipadamente a dónde va con su decisión y cuáles son las repercusiones que podrían darse en el necesitado; además, este deberá considerar si el ofrecimiento de sí es evangélicamente prudente y proporcional a las necesidades del prójimo y al efecto beneficioso que podría efectivamente derivarse del mismo. El ofrecimiento de la vida es un acto de amor que debe tener su racionalidad, no puede ser provocado por motivaciones banales ni utilizarse para resolver situaciones objetivamente sin solución (al modo de don Quijote). Para que el ofrecimiento no se convierta en un delirio, utopía o espejismo deberá adherirse a la realidad del mismo modo como puede ser percibida por una mente sana, prudente e iluminada por la fe. Los jueces deberán verificar el espíritu de caridad, de paciencia, de mansedumbre, de paz y de humildad que ha perseverado en quien se ofrece hasta el final. También se deberá ver si quien se ofrece por el prójimo no se sustrae de ese modo a los derechos fundamentales de otros, a los cuales se ha vinculado con obligaciones de justicia.

\section{Cuarto criterio: existencia de la fama de santidad y de signos, al menos después de la muerte}

Normalmente, las causas de beatificación y canonización suben desde abajo, porque es el pueblo de Dios, en sus diferentes articulaciones, quien ve e indica a los obispos, a los campeones de la fe y a los merecedores 
del honor en los altares. La fama de santidad es materia tan importante que el Código de 1917 preveía un específico proceso diocesano para verificar su existencia y genuinidad. Tal investigación era decisiva al punto que una causa no podía ir adelante sin la demostración de que tal fama fuese "espontánea, no creada artificialmente o construida por intereses humanos, compartida por personas serias y honestas, continua, aumentada en el tiempo y viva entre la mayor parte del pueblo", así rezaba el $\$ 2$ del canon 2050 del Código de 1917, el cual se refería a un documento de Urbano VIII, del 12 de marzo de 1631. La importancia jurídica de la fama de santidad es reconocida también hoy y vinculada a su relevancia teológica. En efecto, es opinión común que el autor último de una verdadera fama de santidad es Dios mismo, quien toma la iniciativa de indicar a su pueblo cuales son los cristianos que desea glorificar en la Iglesia. Aquí alguien podría justamente observar que la atención a la fama de santidad es también atención a la voluntad de Dios y viceversa.

El acto heroico de ofrecer la vida no es un hecho común y frecuente por lo que no puede no llamar la atención. La admiración, además, puede derivar en imitación e invocación; tal resultado es lo que llamamos fama de santidad. En la carta del 24 de abril de 2006, con ocasión de una Plenaria de la Congregación para las Causas de los Santos, Benedicto XVI (2006) escribía:

No se podrá iniciar una causa de beatificación y canonización si falta una comprobada fama de santidad, incluso si nos encontramos ante personas que se han distinguido por coherencia evangélica y por especiales benemerencias eclesiales y sociales. (p. 495)

\section{Quinto criterio: necesidad del milagro para la beatificación acontecido después de la muerte del Siervo de Dios y por su intercesión}

La misma cosa se requiere para la beatificación de los Siervos de Dios que ya han obtenido el reconocimiento de la heroicidad de las virtudes teologales, cardinales y anejas. También en el supuesto del ofrecimiento de la vida el milagro es la ratificación de Dios al juicio "humano" emitido por la Congregación. Benedicto XVI (2006) escribía en la citada carta:

Además de asegurarnos [de] que el Siervo de Dios vive en el cielo en comunión con Dios, los milagros constituyen la divina confirmación del juicio expresado por la autoridad eclesiástica sobre la vida virtuosa [...]. La praxis ininterrumpida de la Iglesia establece la necesidad de un milagro físico, no siendo suficiente un milagro moral. (p. 496)

\section{Algunos ejemplos}

Con el tiempo, la Iglesia tendrá santos y beatos que han llegado al honor de los altares gracias al don de sí, usque ad mortem. También en el pasado ha habido este género de heroico testimonio, pero, como se ha dicho, no ha podido reconocerse sino en el ámbito del martirio (véase san Maximiliano María Kolbe) o de las virtudes heroicas, como en los casos que aquí referimos a modo de ejemplo:

San Girolamo Emiliani (1486-1537) fue víctima de la asistencia a los apestados.

La peste que afectó a Somasca a principios del 1537, vio de nuevo a Girolamo prodigarse en la asistencia [...] de los afectados por la terrible enfermedad, de la que quedó inexorablemente también él mismo contagiado [...]. Amanecía el 8 de febrero de 1537, cuando Girolamo, víctima de su misma abnegación y mártir de la caridad, terminó santamente en Somasca, en el nombre de María, su laboriosa jornada terrena. (Instituto Giovanni XXIII y Pontificia Universidad Lateranense, 1961)

San Luigi Gonzaga (1568-1591), después de muchas insistencias, obtuvo de sus Superiores la dedicación a los apestados de Roma, aun sabiendo el grave riesgo que corría. En efecto, aquella peste fue especialmente agresiva y contagiosa: de una población de aproximadamente cien mil habitantes, murieron sesenta mil. Benedicto XIV refiere el hecho en estos términos: 
En el año 1591 hubo en Roma una gran carencia de alimentos que dio origen a una epidemia que causó la muerte a sesenta mil personas. San Luigi Gonzaga se puso al servicio de los enfermos en los hospitales [...]. Los auditores de la Rota juzgaron que la muerte de Luigi fue una especie de martirio. (Benedicto XIV, 2015, n.o 9)

San Damian de Veuster (1840-1889) partió para las islas Hawai en 1863, en lugar de su hermano Panfilo, que había enfermado. En mayo de 1873, voluntariamente, se ofreció para asistir "para siempre" a los leprosos en la isla de Molokai. "Su generosidad lo condujo bien pronto a un amor sin medida por el prójimo y a un espíritu de sacrificio total” (Geen, 1969, p. 1665). Contrajo lepra en 1885 y murió en 1889. La causa de beatificación procedió, como era justo, por viam virtutum, aunque para muchos padres Damian era un verdadero mártir. Su calvario fue tan largo que tuvo el tiempo necesario (diuturnitas) para adquirir las virtudes heroicas y por ello llegar a la beatificación por esta vía.

Santa Gianna Beretta in Molla (1922-1962) maduró su vida cristiana en la familia, en la acción católica y en la profesión médica; se casó en 1955, vivió ejemplarmente su fe como esposa y madre. Durante el tercer embarazo tuvo que ser sometida a una delicadísima operación de ovarios, la consigna dada por ella misma a los médicos fue: "salvad a mi criatura". Contra el parecer de todos, llevó a término su embarazo. Una semana después del parto murió víctima de su sacrificio para salvar a su hija.

\section{Conclusión}

El motu proprio introduce oficialmente en los procedimientos para la beatificación un nuevo modelo de santidad canonizable, el del seguimiento de Cristo en el acto más heroico de su misión y más comprometido, si así se puede decir, de amor por el Padre y por la humanidad. El documento tiene, sobre todo, un valor teológico y espiritual. En otras palabras, quien se ofrece hasta el don supremo de sí escribe en su carne otra página del Evangelio, de la teología y de la historia de la Iglesia. Aunque "los teólogos no se han interesado verdaderamente de los santos" (Beinert, 1985, p. 53), estos hermanos nuestros nos ofrecen una clave especial para entrar en el misterio de Cristo.

El teólogo Benedicto XVI (2008), en la audiencia del 17 de diciembre de 2007, a los que trabajan en las causas de los santos les decía que

los Santos y los Beatos son casi una ilustración viva de los dos aspectos de la perfección del Divino Maestro [...] y, correctamente presentados, en su dinamismo espiritual y en su realidad histórica contribuyen a hacer más creíble y atrayente la palabra del Evangelio y la misión de la Iglesia.

Por su parte, Von Balthasar escribía que "los santos de la Iglesia son el comentario más importante del Evangelio, porque esos son la interpretación encarnada de la palabra encarnada de Dios y son realmente, por lo tanto, una vía de acceso a Jesús" (Herbstrith, 1982, pp. 186-187). En 2010, el cardenal Angelo Amato (2010), teólogo y prefecto de la Congregación para las Causas de los Santos, en una de sus numerosísimas publicaciones de carácter hagiográfico, escribía:

Hoy, más que nunca, urge una teología sapiencial, que haga síntesis entre investigación teológica y teología vivida de los santos, entre scientia fidei y scientia amoris. Quizá el tiempo está ya maduro para valorizar al máximo en teología el locus hagiographicus, como convencido instrumento de comprensión y de expresión de la verdad contenida en el misterio de Cristo y de la Iglesia. (p. 39)

Como el Evangelio es una mina que no dejará de sorprendernos y de enriquecernos, también la aplicación del Evangelio a la vida podrá tener recorridos y testimonios siempre nuevos y quizá imprevisibles. Esto significa que la tipología de los santos canonizados no es un hortus conclusus y no puede quedar ceñida a esquemas y modelos demasiados rígidos. A la luz de este principio, en los años sucesivos al Vaticano II, la Congregación para las Causas de los Santos no se ha limitado a revisar los procedimientos, como ya se ha 
dicho, sino que se ha abierto a profundizaciones teológicas que han dado lugar a nuevas oportunidades a las causas de los santos. A continuación, recordaré solo algunas de estas etapas:

1. En 1981, la Plenaria de los cardenales y obispos del dicasterio reconoció que los niños (7-14 años) son capaces de practicar las virtudes en grado heroico y de afrontar un verdadero martirio ${ }^{[\$ s \delta s s \delta s]}$. El resultado de aquella decisión teológica desbloqueó algunas causas, entre ellas la de los niños de Fátima (Francisco y Jacinta Marto, ya canonizados), Galileo Nicolini, Laura Vicuña y Maggiorino Vigolungo, pero el fruto más sorprendente fue el reconocimiento de las virtudes heroicas de Antonietta Meo (Nennolina), que murió cuando tenía seis años y medio.

2. El mismo año, la misma Plenaria abordó el examen de los criterios para el otorgamiento del título de Doctor de la Iglesia. Ya Pablo VI en 1972 había decidido revisar toda la materia. De ello derivó una Instrucción sobre el otorgamiento del título de Doctor de la Iglesia[ ${ }^{* * * * * * *}$, que guio a la Congregación en la atribución del doctorado a santa Teresa del Niño Jesús (Juan Pablo II, 1997), san Juan de Ávila (Benedicto XVI, 2012), santa Hildegarda de Bingen (Benedicto XVI, 2012) y san Gregorio de Narek (Papa Francisco, 2015).

3. En 2008, los consultores teólogos y, después, los cardenales y obispos del Dicasterio para las Causas de los Santos y para la Doctrina de la Fe, en la sesión conjunta del 17 de diciembre de 2008, discutieron si a los santos mártires se les podía conceder el título de Doctor de la Iglesia universal ${ }^{[\dagger \dagger+\uparrow \dagger+t]}$. Hasta entonces ningún mártir había tenido tal título, puesto que se consideraba preeminente el título de mártir y se pensaba que no era conveniente añadir otros. Los padres decidieron que no existe alguna incompatibilidad metafísica entre el título de mártir y el de doctor. De todas formas, los padres favorables a la unión de los dos títulos propusieron una investigación sobre la eminens doctrina así como sobre la práctica de las virtudes heroicas de los mártires antiguos.

4. En 1955, la causa del capitán Guido Negri fue archivada por Pío XII; Juan XXIII, sin embargo, permitió que se procediese ad ulteriora. Pablo VI, en 1973, detuvo de nuevo dicha causa, que, desde entonces, no se ha movido, junto con la de otros militares, con algunas excepciones bajo los pontificados de Juan Pablo II y Benedicto XVI (por ejemplo, las causas del beato Faà di Bruno y del beato Carlos de Austria). La Plenaria de los cardenales y obispos, del 16 de abril de 2013, discutió si los militares pueden ser beatificados y canonizados y, en caso de que fuera posible, si ello era oportuno. La conclusión, compartida por el Santo Padre (en fecha 2 de mayo de 2013), recita:

En síntesis, se puede notar convergencia en las respuestas a las dos partes de la duda: por un lado, no se ve obstáculo intrínseco al hecho de que un militar sea beatificado o canonizado; por otro lado, se considera generalmente que la cuestión de la oportunidad tenga que ser examinada, caso por caso, por la Congregación para las Causas de los Santos y, obviamente, sometida al juicio del Romano Pontífice. Algunos miembros han subrayado también la oportunidad pastoral, en concreto para los castrenses, de la beatificación y canonización de militares. ${ }^{[\neq \neq \neq \neq \neq \neq \neq \neq \neq]}$

El motu proprio Maiorem hac dilectionem es la última etapa de un camino que el Papa Francisco ofrece como una nueva oportunidad para la Iglesia y, en particular, para los pastores, los teólogos, los juristas y a cuantos promueven las causas de los santos y buscan el esplendor de Cristo en su rostro.

\section{Referencias}

Amato, A. (2010). I santi nella Chiesa. Roma: Librería Editrice Vaticana.

Bartolucci, M. (1992). Attività del cardinale Giuseppe Casoria nelle cause dei santi. En G. Casoria, A. Moroni, C. Pinto y M. Bartolucci, Sacramenti, liturgia, cause dei santi. Nápoles: Campania Notizie.

Bartolucci, M. (2017a). La cuarta vía. La Voz de los Obispos. Recuperado de https://lavozdelosobispos.wordpress.co $\mathrm{m} / 2017 / 07 / 15 /$ la-cuarta-via/

Bartolucci, M. (2017b, 11 de julio). La cuarta vía: un nuevo caso en el iter procesal de las canonizaciones. L'obsservatore Romano. Recuperado de http://www.osservatoreromano.va/es/news/la-cuarta 
Bartolucci, M. (2017c). L'amore più grande: dare la vita per i fratelli. En Congregazione delle Cause dei Santi, L'offerta della vita nelle cause dei santi. Roma: Librería Editrice Vaticana.

Beinert, W. (1985). Il culto deis anti oggi. Milán: San Pablo.

Benedicto XIV. (2010). La beatificazione dei Servi di Dio e la canonizzazione dei Beati (vol. 1). Roma: Librería Editrice Vaticana.

Benedicto XIV. (2015). La beatificazione dei Servi di Dio e la canonizzazione dei Beati (vol. 3). Roma: Librería Editrice Vaticana.

Benedicto XV. (1917). Pio-Benedictine code of canon law (Edward N. Peters, curador). San Francisco: Ignatius Press. Benedicto XVI. (2006). Insegnamenti di Benedetto XVI (vol. 1). Roma: Librería Editrice Vaticana.

Benedicto XVI. (2008). Insegnamenti di Benedetto XVI (vol. 3). Roma: Librería Editrice Vaticana.

Cesaréia, E. de. (2008). Historia eclesiástica. Madrid: Biblioteca de Autores Cristianos. Recuperado de https://es.scrib d.com/document/213702438/Eusebio-de-Cesarea-Historia-eclesiastica-bilingue-pdf

Comisión Pontificia para el Estado de la Ciudad del Vaticano. (2008). Bollettino n. 18. Regolamento Generale per il Personale del Governatorato dello Stato della Città del Vaticano. Recuperado de http://www.vatican.va/roman_ curia/labour_office/docs/documents/ulsa_b18_7_it.html

Congregación para las Causas de los Santos. (1983). Normae servandae in inquisitionibus ab Episcopisfacendis in Causis Sanctorum. Acta Apostolicae Sedis, año y volumen 75, parte II, 396-403. Recuperado de http://www.vatican.va /archive/aas/documents/AAS-75-1983-I-ocr.pdf

Congregación para las Causas de los Santos. (2007). Acta Congregationum. Acta Apostolicae Sedis, año y volumen 99, 465-510. Recuperado de http://www.vatican.va/archive/aas/documents/2007/giugno\%202007.pdf

Cozzoli, M. (2010). Etica teologale: fede, carità, speranza. Cinisello Balsamo: San Pablo.

Criscuolo, V. (2018). La positio sulle virtu e sul martirio: significato, composizione, struttura. En V. Criscuolo, C. Pellegrino y R. J. Sarno (eds.), Le cause dei Santi(pp. 307-344). Roma: Librería Editrice Vaticana.

Francisco. (2017). Carta apostólica en forma de motu proprio sobre el ofrecimiento de la vida. Congregazione delle Cause dei Santi. Recuperado de http://www.causesanti.va/it/documenti/maiorem-hac-dilectionem-espanol.html

Francisco. (2018). Exhortación apostólica Gaudete et exsultate, sobre la llamada a la santidad en el mundo contemporáneo. Vatican.va. Recuperado de http://w2.vatican.va/content/francesco/es/apost_exhortations/d ocuments/papa-francesco_esortazione-ap_20180319_gaudete-et-exsultate.html

Gangoiti, B. (1992). Verso un "sensus plenior" del martyrio. En G. M. Casoria, A. Moroni, C. Pinto y M. Bartolucci, Sacramenti, liturgia, cause dei santi: studi in onore del cardinale Giuseppe Casoria (pp. 589-604). Nápoles: Campania Notizie.

Geen, G. (1969). Veuster Damiano. En Istituto Giovanni XXIII della Pontificia Università Lateranense, Bibliotheca sanctorum (vol. 11). Roma: Autor.

Herbstrith, W. (ed.). (1982). Teresa d'Avila: la vita, il pensiero, l'idetità di donna. Roma: Cittá Nuova.

Instituto Giovanni XXIII, y Pontificia Universidad Lateranense. (1961). Bibliotheca sanctorum. Roma: autor.

Juan Pablo II. (1983). Constitutio apostolica Divinus perfectionis Magister. Acta Apostolicae Sedis, año y volumen 75, parte II, 349-355. Recuperado de http://www.vatican.va/archive/aas/documents/AAS-75-1983-I-ocr.pdf

Misztal, H. (2005). Le cause di canonizzazione. Storia e procedura. Roma: Librería Editrice Vaticana.

Nuova via per la santità. Il cardinale Amato sul motuproprio "Maiorem hac dilectionem". (2017, 25 de agosto). L'Osservatore Romano. Recuperado de http://www.osservatoreromano.va/it/news/nuova-la-santita

Pablo VI. (1964). Vaticano II. Lumen Gentium. Recuperado de http://www.vatican.va/archive/hist_councils/ii_vati can_council/documents/vat-ii_const_19641121_lumen-gentium_sp.html\#*

Pablo VI. (1969). Litterae apostolicae Motu Proprio datae: Processus de Causis beatificationis et canonizationis aptius ordinantur. Acta Apostolicae Sedis, año y volumen 51, 149-153. Recuperado de http://www.vatican.va/archive/ aas/documents/AAS-61-1969-ocr.pdf 
Porporatto, M. (2015, 16 de julio). Significado de "a corto plazo". Que significado. Recuperado de https://quesignific ado.com/a-corto-plazo/

Real Academia Española. (2018). Por lo menos; al menos. Edición Tricentenario. Rae.es. Recuperado de https://dle. rae.es $/$ ?id $=$ OuzZNmN

Secretaría de Estado. (1999). Regolamento Generale della Curia Romana. Recuperado de http://www.vatican.va/ro man_curia/secretariat_state/1999/documents/rc_seg-st_19990430_regolamento-curia-romana_it.html

Tagliaferri, M., y Borer, J. (2017). Santi e Beati Giovani. Roma: Librería Editrice Vaticana.

Thils, G., y Bussi, N. (1960). Santita\# cristiana: compendio di teologia ascetica. Alba: Ediciones Paulinas.

\section{Notas}

\section{* Artículo de reflexión}

[**] El Papa Francisco estableció en el motu proprio que este se promulgaría mediante la publicación en el diario L'Osservatore Romano y que su entrada en vigor sería el mismo día, es decir, el 11 de julio de 2017. En su momento se incorporará el texto en el boletín Acta Apostolicae Sedis.En concreto, se aplicaría el canon n. ${ }^{\circ} 8$ del Código de Derecho Canónico (CIC) (1983), según el cual está previsto que, en casos particulares, la promulgación y, por tanto, la publicación de una ley universal pueda acontecer diversamente como está indicado en el $\$ 1$ del citado canon, es decir, no en Acta Apostolicae Sedis, pues, por su misma naturaleza, puede entrar en vigor inmediatamente, por lo que no existe vacación de la ley.

[***] Si bien no hay una definición estándar acerca de la duración de estos periodos, ya que cada persona puede aplicar su criterio personal en la determinación de los plazos de acuerdo a su conveniencia, hay criterios aceptados convencionalmente. "A corto plazo" es una expresión utilizada, en especial, en economía para designar la duración de periodos breves (habitualmente de pocos meses) (Porporatto, 2015). En general, se consideran "a corto plazo" aquellos periodos de hasta aproximadamente un año. Sin embargo, para algunos traders, "corto plazo" son algunas horas, "mediano plazo" son algunos pocos días y "largo plazo" no más de una semana. En contabilidad, se define como "corto plazo" a los activos de inmediata disponibilidad, como bancos, caja, clientes y documentos por cobrar. También a los pasivos que se liquidarán dentro del ejercicio de 12 meses se los considera obligaciones "a corto plazo". Las deudas gubernamentales "a corto plazo" son aquellas cuyos vencimientos operan dentro del año. En el mercado bursátil, las inversiones "a corto plazo" son aquellas cuyo panorama es en promedio de 180 días, pero si la tendencia al alza del mercado es pronunciada, el panorama de inversión de corto plazo es de uno o dos meses y, a veces, menos de un mes. En el área de la biología hablamos de memoria "a corto plazo". El ser humano no tiene solo una memoria, sino que coexisten en el cerebro varios tipos de memoria que se integran como un todo y funcionan como una red, pero con total independencia una de otra. La memoria a corto plazo se integra por la memoria perceptiva (captación sensorial a través de los sentidos) y la memoria operativa o del trabajo permite a la persona actuar en el presente por medio de la relación de habilidades y recuerdos del pasado que están guardados en la memoria a largo plazo (Porporatto, 2015). El pronóstico elaborado en los centros de investigación y servicios meteorológicos nacionales e internacionales se extiende a 96 horas. Una visa Schengen se emite con el propósito de una "corta estancia" (menos de 90 días) en Dinamarca y otros países de la Región de Schengen. En agricultura "corto plazo" hace referencia al periodo de tiempo que no supera el ciclo de explotación, no suele pasar de doce meses. En ámbitos universitarios, crédito directo a corto plazo es la modalidad de crédito a seis meses que puede ser solicitada por un estudiante para el pago de su orden de matrícula. Por Docentes de corto plazo se entiende la docencia de un profesor, también extranjero, por un periodo mínimo de 1 mes y máximo de 6 meses. En síntesis, según definición.org, "corto plazo" es el periodo convencional generalmente hasta de un año, en el que los programas operativos determinan y orientan en forma detallada las decisiones y el manejo de los recursos para la realización de acciones concretas. En contabilidad se define así a los activos de disponibilidad inmediata como: caja, bancos, clientes y documentos por cobrar. Igualmente, a los pasivos que se han de liquidar en el lapso de un año se les concibe como obligaciones de corto plazo. Por su lado, la deuda gubernamental entiende como de corto plazo a aquélla cuyo vencimiento ocurre en un periodo menor al año. En el terreno bursátil se debería entender por corto plazo a aquellas inversiones que tienen un panorama de 180 días como promedio; sin embargo, cuando un mercado tiene una tendencia pronunciada al alza es común entender por corto plazo panoramas de inversión de dos o tres meses, o incluso menos de un mes.

[****] Entrevista publicada en L'Osservatore Romano el 25 de agosto de 2017 (edición en lengua italiana) ("Nuova via per la santità", 2017).

[*****] Esta información fue tomada de un archivo privado de la Congregación para las Causas de los Santos.

[******] Información tomada de un archivo privado de la Congregación para las Causas de los Santos.

[*******] Información tomada de un archivo privado de la Congregación para las Causas de los Santos.

[†t] El documento original, en lengua italiana, contiene los siguientes documentos: Presentazione, por Vincenzo Criscuolo (p. 3); Lettera Apostolica in forma di motu proprio Maiorem hac dilectionem sull'offerta della vita, por el Papa Francisco 
(pp. 5-12); L'offerta della vita nelle Cause dei Santi, por Marcello Bartolucci (pp. 13-26); Nuova via per la Santità, por Angelo Amato (pp. 27-32), y L'amore più grande: dare la vita per i fratelli (pp. 33-72) e Índice (pp. 73-76), por Marcello Bartolucci.

[キ‡] El inicio del Colegio de Postuladores se remonta a los años 1925-1926, cuando algunos postuladores sintieron la necesidad de consultarse entre ellos y de unirse en una pía asociación que, sirviéndose de experiencias comunes, pudiera beneficiar a los postuladores para dar una colaboración más eficaz a la que entonces era la Sagrada Congregación de Ritos. La iniciativa y el trabajo llevado a cabo fueron apreciados por el Papa Pío XII con ocasión del treinta aniversario de la fundación del Colegio. El 14 de marzo de 1927 fue constituido el Colegio en la casa generalicia de la Compañía de Jesús, en presencia del postulador general de los Jesuitas, de los Sulpicianos, Carmelitas Descalzos, Franciscanos Menores, Capuchinos, Redentoristas y Eudistas. En lo que se refiere a la finalidad de esta asociación, hay que decir que, desde su constitución, es la de ofrecer una ayuda a los postuladores y una eficaz colaboración con la Congregación para las Causas de los Santos, por medio de reuniones de estudio, para favorecer el intercambio de ideas, conocimientos y experiencias, y también para dar uniformidad a la acción. Desde entonces numerosas temáticas que han sido progresivamente tratadas y discutidas, ya que se consideran actuales y necesitadas de profundización. Dentro de estas hay un vasto abanico que va desde cuestiones teológicas a problemas de teología ascética y mística, de temas teológico-jurídico a argumentos de índole histórica, psicológica y clínica. Así mismo, hay que destacar la paciente y perseverante actividad que el Colegio desarrolla en contacto y colaboración con la Congregación para las Causas de los Santos.

[\$§] El Congreso Ordinario está formado por el prefecto, el secretario, el subsecretario, el promotor de la fe y el relator general. En este también participa también el jefe del servicio, así como, solo si es necesario, el relator o los oficiales encargados de estudiar directamente la práctica que se tratará en el Congreso. El relato verbal es redactado por un oficial de la Congregación que, a su vez, es elegido por el prefecto. Al Congreso se someten los votos sobre la validez jurídica de las investigaciones diocesanas o eparquiales y las instancias de mayor importancia sobre el desarrollo de las causas presentadas por los obispos o por los postuladores de las mismas, así como otras cuestiones indicadas por el prefecto. Para ampliar la información sobre este tema, véase Comisión Pontificia para el Estado de la Ciudad del Vaticano (2008, arts. 24-25).

[***] Positio es el término que, en el lenguaje de la Curia Romana, indica la relación, el informe o el dossier concerniente a una determinada cuestión o argumento particular. Cuando la Positio se estudia y discute en las reuniones oficiales (congresos o congregaciones) todo el dossier se imprime y, por lo tanto, se hace pública. En la Congregación para las Causas de los Santos se usa, desde sus orígines, como Congregación de Ritos y se usa para las causas de beatificación y canonización o para cuestiones de mayor relieve sobre competencias específicas de la Congregación (reliquias o atribución del título de Doctor de la Iglesia, etc.). En el curso de los años, la composición de la Positio ha experimentado varias estructuras y contenidos. Sobre el significado, la evolución y las actuales indicaciones para su elaboración, véase Criscuolo (2018).

[†††] El Congreso Peculiar es uno de los órganos colegiales de la Congregación; en este, los consultores teólogos se reúnen para pronunciarse sobre cuestiones atinentes a su materia de modo colegial, es decir, presididos por el promotor de la fe. Así mismo, los consultores históricos y los peritos médicos son presididos por el relator general o por el presidente del albo (en el caso de la Consulta Médica) con el fin de pronunciarse sobre la duda propuesta por la Congregación según los casos.

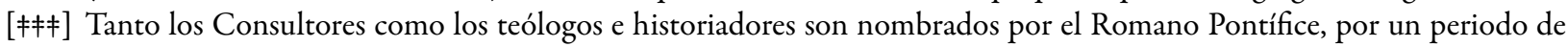
cinco años. En casos particulares, el prefecto puede nombrar consultores ad actum. Algunas Positiones, antes de ser objeto de estudio de parte de los teólogos, se someten al examen previo de los consultores históricos, y es así como son llamados a pronunciarse sobre el aspecto científico del material, es decir, sobre la cualidad de la documentación y sobre la suficiencia de la misma para los fines de la causa. Su juicio constituye, para los teólogos, la garantía de poseer una base histórica sólida para pronunciarse sobre el mérito de la causa. El estudio de los historiadores tiene el carácter de una pericia y no se pronuncian sobre la santidad del siervo de Dios. Si la mayoría de los consultores historiadores interpelados encuentra que la Positio es insuficiente, desde el punto de vista de la documentación archivística, y que no es posible remediar con ulteriores estudios, la Positio no se transmite a los consultores teólogos.Por lo que respecta al Congreso peculiar de los Consultores Teólogos, los consultores son llamados a pronunciarse en base a los testimonios y documentos recogidos, y críticamente presentados en la Positio, sobre el martirio, la heroicidad de las virtudes o el ofrecimiento de la vida y sobre la fama de santidad y los signos de un Siervo de Dios. La respuesta que pueden dar es Afirmativa, Afirmativa ad mentem, Negativa o Suspensiva.

[\$§§] La Sesión Plenaria de la Congregación es la reunión de todos los cardenales y obispos de todo el mundo y miembros de la Congregación; estos son convocados para una fecha previamente concordada con la Secretaría de Estado. Para ampliar la información sobre este tema, véase el Reglamento General de la Curia Romana (Secretaría de Estado, 1999, art. 102).

[ $+\uparrow+\uparrow] \mathrm{La}$ "consciencia" es la capacidad del ser humano de reconocer la realidad circundante y de relacionarse con ella, es el conocimiento reflexivo de las cosas, inmediato o espontáneo, que el sujeto tiene de sí mismo, de sus actos y reflexiones. En psicología, se entiende por “consciencia” al acto psísquico por el que un sujeto se percibe a sí mismo en el mundo.

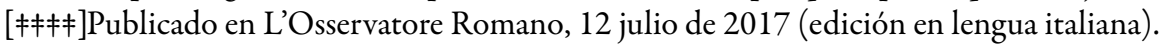

[\$\$\$\$] Si resultan probados el ofrecimiento de la vida hasta la muerte a motivo de la caridad, así como las virtudes cristianas ejercitadas al menos en grado ordinario, en el caso y para las finalidades de que se trata. 
$[+\uparrow+\uparrow \dagger]$ Encuentro con el Colegio de Postuladores del 20 de noviembre de 2017.

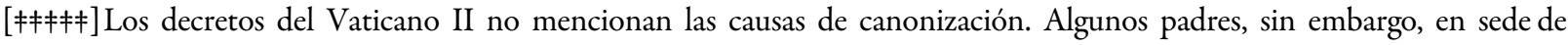
congregación plenaria, expresaron el deseo de dar más espacio a las causas de laicos y a las causas no europeas. Lamentaban, además, la lentitud del procedimiento y su costo.

[\$\$\$\$\$] Una sintética descripción de la situación interna de la Congregación en aquellos años se ofrece en "Attività del cardinale Giuseppe Casoria nelle cause dei santi” (Bartolucci, 1992), del libro Sacramenti, liturgia, cause dei santi.

[††††††] Información tomada de un archivo privado de la Congregación para las Causas de los Santos.

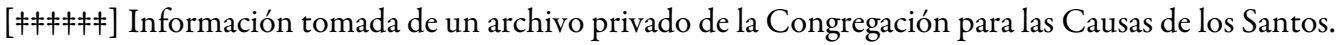

[ \$\$\$\$] L' Osservatore Romano, 24 septiembre 2016, 8 (edición en lengua italiana).

[t††††† ] Información tomada de un archivo privado de la Congregación para las Causas de los Santos.

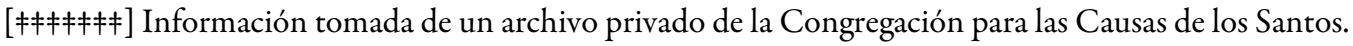

\$\$\$\$ $]$ Para ampliar la información sobre este tema véase Istruzione redatta ad uso di quanti si occupano delle Cause di beatificazione e canonizzazione degli adolescenti, firmada por el prefecto cardenal P. Palazzini y por el secretario G. Casoria y aprobada por Juan Pablo II el 4 de mayo de 1981.

[†t†††††] Información tomada de un archivo privado de la Congregación para las Causas de los Santos.

[キキキキキキキキ] Información tomada de un archivo privado de la Congregación para las Causas de los Santos.

\section{Licencia Creative Commons CC BY 4.0}

Cómo citar este artículo: Hernández Rodríguez, M. V. (2019). Algunas reflexiones a propósito de la nueva vía en las causas de los santos. Universitas Canónica, 35(51). https://doi.org/10.11144/Javeriana.ucan35-5 1.arpn 